\title{
Neuropeptidergic Signaling Partitions Arousal Behaviors in Zebrafish
}

\author{
Ian G. Woods, ${ }^{1,2}$ David Schoppik, ${ }^{2}$ Veronica J. Shi, ${ }^{2}$ Steven Zimmerman, ${ }^{2}$ Haley A. Coleman, ${ }^{1}$ Joel Greenwood, ${ }^{3}$ \\ Edward R. Soucy, ${ }^{3}$ and Alexander F. Schier ${ }^{2,3}$ \\ ${ }^{1}$ Department of Biology, Ithaca College, Ithaca, New York 14850, and ${ }^{2}$ Department of Molecular and Cellular Biology and ${ }^{3}$ Center for Brain Science, Harvard \\ University, Cambridge, Massachusetts 02138
}

\begin{abstract}
Animals modulate their arousal state to ensure that their sensory responsiveness and locomotor activity match environmental demands. Neuropeptides can regulate arousal, but studies of their roles in vertebrates have been constrained by the vast array of neuropeptides and their pleiotropic effects. To overcome these limitations, we systematically dissected the neuropeptidergic modulation of arousal in larval zebrafish. We quantified spontaneous locomotor activity and responsiveness to sensory stimuli after genetically induced expression of seven evolutionarily conserved neuropeptides, including adenylate cyclase activating polypeptide $1 \mathrm{~b}$ (adcyap1b), cocaine-related and amphetamine-related transcript (cart), cholecystokinin (cck), calcitonin gene-related peptide (cgrp), galanin, hypocretin, and nociceptin. Our study reveals that arousal behaviors are dissociable: neuropeptide expression uncoupled spontaneous activity from sensory responsiveness, and uncovered modality-specific effects upon sensory responsiveness. Principal components analysis and phenotypic clustering revealed both shared and divergent features of neuropeptidergic functions: hypocretin and cgrp stimulated spontaneous locomotor activity, whereas galanin and nociceptin attenuated these behaviors. In contrast, cart and adcyaplb enhanced sensory responsiveness yet had minimal impacts on spontaneous activity, and cck expression induced the opposite effects. Furthermore, hypocretin and nociceptin induced modality-specific differences in responsiveness to changes in illumination. Our study provides the first systematic and high-throughput analysis of neuropeptidergic modulation of arousal, demonstrates that arousal can be partitioned into independent behavioral components, and reveals novel and conserved functions of neuropeptides in regulating arousal.
\end{abstract}

\section{Introduction}

Arousal is fundamental to life, from the vigilance required to hunt prey or avoid predators, to the drive needed to obtain sustenance and mates. Defects in arousal can be debilitating. For the $\sim 15-20 \%$ of Americans with sleep disorders, approximately half exhibit insomnia, which is associated with an inability to regulate physiological arousal (Mahowald and Schenk, 2005; Colten and Altevogt, 2006; Saper et al., 2010). Inappropriately elevated arousal is associated with stress, anxiety, and hyperactivity, whereas abnormally low arousal can cause inattention, excessive sleepiness, chronic fatigue, and vegetative states (Pfaff and Banavar, 2007; Pfaff et al., 2008; Berridge et al., 2010). Nearly a century of research has elucidated the primary arousal-promoting neuroanatomy: ascending projections from brainstem nuclei stimulate wakefulness in the brain (von Economo, 1930; Moruzzi and

Received Aug. 16, 2013; revised Jan. 1, 2014; accepted Jan. 7, 2014.

Author contributions: I.G.W., D.S., and A.F.S. designed research; I.G.W., V.J.S., and H.A.C. performed research; I.G.W., D.S., S.Z., J.G., and E.R.S. contributed unpublished reagents/analytic tools; I.G.W. analyzed data; I.G.W. and A.F.S. wrote the paper.

This work was supported by a postdoctoral fellowship from the American Cancer Society (PF-07-262-01-DDC to I.G.W.), by a Helen Hay Whitney postdoctoral fellowship (to D.S.), by the McKnight Endowment Fund for Neuroscience (to A.F.S.), and by the National Institutes of Health (R01HL109525 to A.F.S.). We thank Constance Richter for critical reading of the manuscript.

The authors declare no competing financial interests.

Correspondence should be addressed to either of the following: Ian G. Woods at the above address. E-mail: iwoods@ithaca.edu; or Alexander F. Schier at the above address. E-mail: schier@fas.harvard.edu.

DOI:10.1523/JNEUROSCI.3529-13.2014

Copyright $\odot 2014$ the authors $\quad 0270-6474 / 14 / 333142-19 \$ 15.00 / 0$
Magoun, 1949; Saper et al., 2005, 2010; Pfaff and Banavar, 2007; Fuller et al., 2011).

Despite extensive studies of the arousal systems, several important questions remain. For example, the partitioning of arousal into individual behavioral components, including spontaneous locomotor activity and sensory responsiveness, has stimulated debate regarding the independence of different arousal behaviors (Robbins, 1997; Garey et al., 2003; Pfaff, 2006; Jing et al., 2009; Lebestky et al., 2009; Agmo, 2011; Van Swinderen and Andretic, 2011; Yokogawa et al., 2012). In addition, relatively little is known about how external and internal inputs interact to set and maintain appropriate levels of arousal. Neuropeptides are attractive candidates to modulate these inputs (Pfaff et al., 2008; Bargmann, 2012), yet systematic and comparative interrogations of neuropeptide function have been constrained by behavioral variability across experimental conditions.

Larval zebrafish are especially useful for studying the molecular and cellular control of arousal, as they possess a conserved yet relatively simple nervous system and display arousal-associated behaviors similar to mammals (Prober et al., 2006; Burgess and Granato, 2007a,b; Wolman and Granato, 2012; Chiu and Prober, 2013). Moreover, their small size facilitates uniformly controlled analyses of behavior across experimental manipulations. The divergence between fish and other vertebrates, separated by 450 million years of evolution, may also be used to infer the ancestral regulation of arousal states (Kumar and Hedges, 1998; Garrison et al., 2012). 
Table 1. Locomotor behavior analysis of wild-type larvae

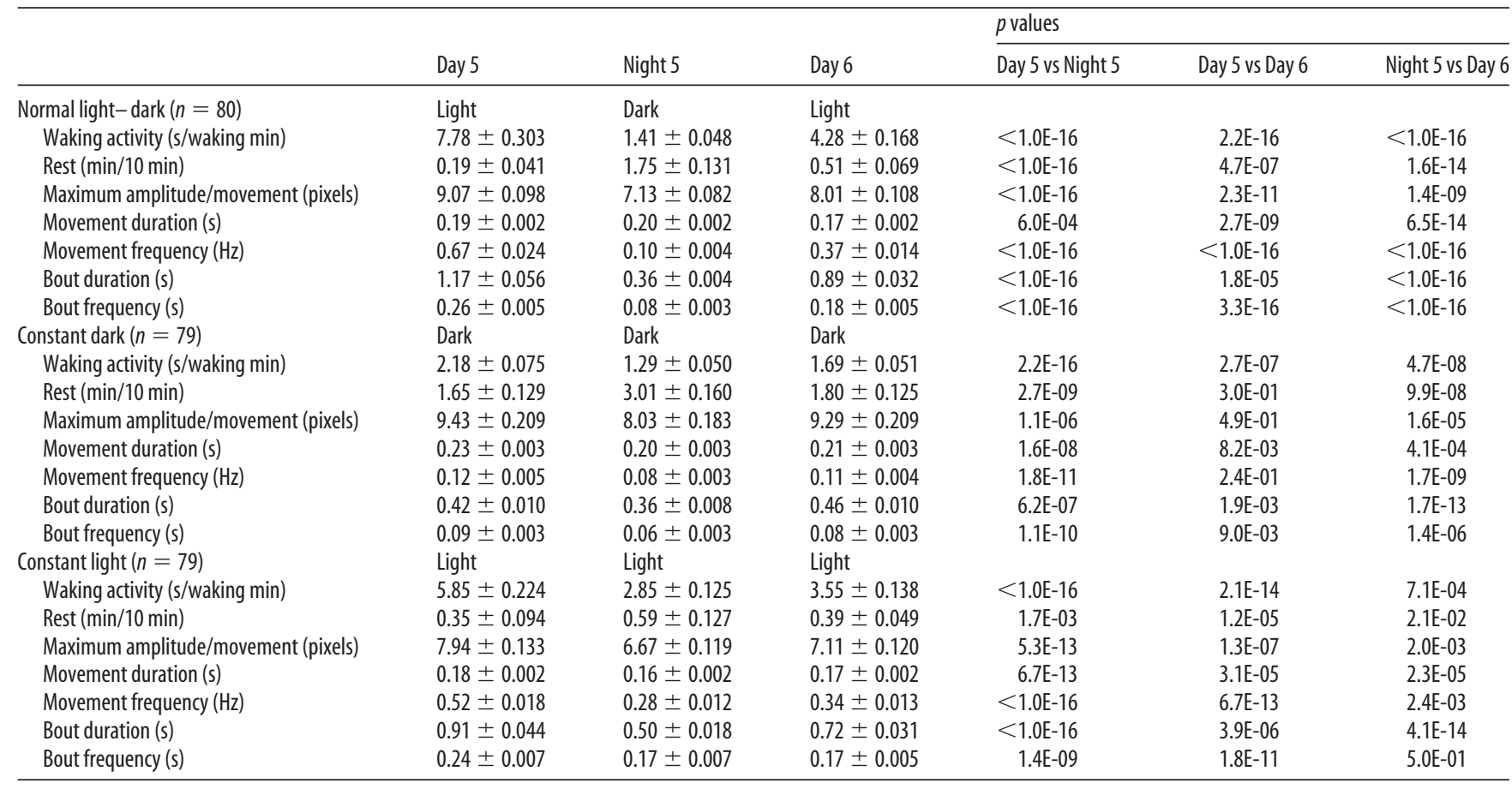

Values are mean \pm SEM $p$ values from Kruskall-Wallis one-way ANOVA.

Here we establish quantitative assays of behavioral arousal by decomposing multidimensional and complex locomotor behaviors into simple parameters (Wolman and Granato, 2012). Via genetic expression of seven evolutionarily conserved neuropeptides [adenylate cyclase activating polypeptide $1 \mathrm{~b}$ (adcyap1b), cocaine-related and amphetamine-related transcript (cart), cholecystokinin (cck), calcitonin gene-related peptide (cgrp), galanin, hypocretin, and nociceptin], we demonstrate that arousal behaviors are behaviorally partitioned: spontaneous locomotor activity can be independent of sensory responsiveness. In addition, we define several novel, unexpected, or conserved functions for neuropeptides. These studies constitute the first quantitative and uniformly controlled comparison of molecular regulators of arousal in vertebrates, partition diverse arousal-associated behaviors, and suggest conserved and novel functions of neuropeptides in regulating arousal.

\section{Materials and Methods}

Generation of transgenic fish. Peptides with discrete patterns of expression in the CNS of larval zebrafish were identified by transcriptome profiling and screening via in situ hybridization (I. G. Woods and A. F. Schier, unpublished observations). Primers were designed to amplify open reading frames of these peptides via RT-PCR (adcyap1b: ATGGCC AGATCTAGTAAAGCG, CTACAAATAAGCAAATCGACGTC; cart: ATGACCATGGAGAGTTCCAAAA, TTACAAACACTTCAACAAAA AGTAATTG; $c c k$ : ATGAGCGCTCTCTCTCCG, TTATGATGAGTATTC ATATTCCTCAGC; $c g r p:$ CCCTCTGTTTTGGGACGACT, AACTGT GGACGTGTGGACTG; galanin: ATGCACAGGTGTGTCGGT, TTAGG GTTGACTGATCTCTTCTGATG; nociceptin: TGAAGTTCCTGCCTCA TTCC, ATGTGACCCGAGCGACCT). PCR amplicons were cloned into a previously described vector (Prober et al., 2006) and verified by sequencing. This vector was modified to be compatible with the tol2 transposon system (Kawakami, 2004) and to include GATEWAY (Life Technologies) recombination sites downstream of the zebrafish heatshock ( $h s p 70 l$ ) promoter. Embryos were injected at the one-cell stage and raised to adulthood. Founder adults were identified by screening for ubiquitous expression of the target gene in heatshocked larval progeny via in situ hybridization. Several founder adults were identified for each peptide; stable transgenic lines were derived from the founders that produced the strongest and most widespread expression upon heatshock. Transgenic larvae in the behavioral analyses were distinguished from their wild-type siblings by PCR. Accession numbers for transcripts in this study are as follows: adcyap1b, NM_214715; cart, BQ480503; cck, BC066290; cgrp, NM_001002471; galanin, EH455016; hypocretin, NM_001077392; nociceptin, NM_001015044. The transgenic line identifiers for transgenes used in this study are as follows: $\operatorname{Tg}($ hsp70l: adcyap1b)a140, $\operatorname{Tg}$ (hsp70l:cart)a137, $\operatorname{Tg}$ (hsp70l:cck)a138, $\operatorname{Tg}$ (hsp701:cgrp) a136, $\operatorname{Tg}$ (hsp70l:galanin)a135, $\operatorname{Tg}$ (hsp70l:hcrt)zf12, $\operatorname{Tg}$ (hsp70l:nociceptin)a139.

Analysis of spontaneous locomotor activity. Larvae were raised at $28.5^{\circ} \mathrm{C}$ on a standard 14/10 h light/dark cycle: lights were turned on at 9 A.M. and off at 11 P.M. Recording of rest/wake activity was performed via infrared Bosch Dinion XF LTC0385 cameras (one-third inch sensors, $752 \times$ 582-pixel resolution; Bosch) as in Prober et al. (2006). Dishes containing 80 larvae of either sex, each in a separate well, were placed in the recording chamber in the evening of the fourth day postfertilization [dpf, $\sim 102 \mathrm{~h}$ postfertilization (hpf)], and were heatshocked at $37^{\circ} \mathrm{C}$ from 12 noon to 1 P.M. on $5 \mathrm{dpf}(\sim 122-123 \mathrm{hpf})$. Analysis of locomotor activity commenced $1 \mathrm{~h}$ postheatshock ( $\sim 124 \mathrm{hpf})$ and continued through $6 \mathrm{dpf}(\sim 157 \mathrm{hpf})$.

For the frame-by-frame $(15 \mathrm{~Hz})$ comparisons between peptideoverexpressing larvae and their wild-type siblings, the raw locomotor data were parsed via Perl and Matlab scripts. A movement was defined as a pixel displacement between adjacent video frames preceded and followed by a period of inactivity of at least $67 \mathrm{~ms}$ (the limit of temporal resolution). A movement bout was defined as a continuous cluster of movements separated by $\leq 1 \mathrm{~s}$ of inactivity. Rest latency was defined as in Prober et al. (2006) as the elapsed time between lights out on $5 \mathrm{dpf}(\sim 133$ hpf) and the first 1 min period of continuous inactivity. Pairwise comparisons between transgenic larvae and their wild-type siblings (Tables 1-3) were performed via Kruskal-Wallis one-way ANOVA and corrected for multiple comparisons via the Holm-Bonferroni method, while comparisons across genotypes (see Fig. 5) were performed using Tukey's honestly significant difference test.

To generate the statistically typical traces of locomotor activity, behavior was examined in $1 \mathrm{~min}$ windows, spaced every $12 \mathrm{~s}$, for each larvae in each experiment. The larva and time period that best matched the aver- 
Table 2. Analysis of locomotor activity in peptide-overexpressing larvae

\begin{tabular}{|c|c|c|c|c|c|c|c|c|c|}
\hline \multirow[b]{2}{*}{ Hypocretin } & \multicolumn{3}{|l|}{ Day 5} & \multicolumn{3}{|l|}{ Night 5} & \multicolumn{3}{|l|}{ Day 6} \\
\hline & Wild type $(n=17)$ & Hypocretin $(n=45)$ & $p$ values & Wild type & Hypocretin & $p$ values & Wild type & Hypocretin & $p$ values \\
\hline Waking activity (s/waking min) & $5.20 \pm 0.534$ & $7.55 \pm 0.320$ & $4.21 \mathrm{E}-04$ & $1.55 \pm 0.188$ & $2.02 \pm 0.109$ & 2.15E-03 & $3.30 \pm 0.404$ & $5.15 \pm 0.320$ & $1.18 \mathrm{E}-03$ \\
\hline Rest (min/10 min) & $1.08 \pm 0.281$ & $0.50 \pm 0.086$ & $8.66 \mathrm{E}-02$ & $4.61 \pm 0.345$ & $1.91 \pm 0.250$ & $3.63 \mathrm{E}-06$ & $1.26 \pm 0.335$ & $0.56 \pm 0.104$ & 2.21E-02 \\
\hline Maximum amplitude/movement (pixels) & $8.43 \pm 0.175$ & $9.19 \pm 0.135$ & $3.79 \mathrm{E}-03$ & $6.70 \pm 0.216$ & $7.82 \pm 0.104$ & $1.11 \mathrm{E}-11$ & $6.83 \pm 0.223$ & $8.04 \pm 0.108$ & $3.44 \mathrm{E}-05$ \\
\hline Movement duration (s) & $0.17 \pm 0.005$ & $0.18 \pm 0.002$ & $1.77 \mathrm{E}-01$ & $0.19 \pm 0.000$ & $0.21 \pm 0.003$ & $1.04 \mathrm{E}-06$ & $0.16 \pm 0.003$ & $0.17 \pm 0.002$ & $2.45 \mathrm{E}-02$ \\
\hline Movement frequency $(\mathrm{Hz})$ & $0.67 \pm 0.058$ & $0.92 \pm 0.034$ & $3.96 \mathrm{E}-04$ & $0.20 \pm 0.025$ & $0.34 \pm 0.018$ & $8.02 \mathrm{E}-12$ & $0.42 \pm 0.050$ & $0.64 \pm 0.035$ & 5.33E-04 \\
\hline Bout duration (s) & $1.76 \pm 0.279$ & $2.25 \pm 0.187$ & $1.91 \mathrm{E}-02$ & $0.67 \pm 0.103$ & $0.76 \pm 0.031$ & $2.59 \mathrm{E}-09$ & $1.07 \pm 0.156$ & $1.47 \pm 0.164$ & $2.08 \mathrm{E}-02$ \\
\hline Bout frequency (s) & $0.19 \pm 0.013$ & $0.22 \pm 0.008$ & $8.12 \mathrm{E}-02$ & $0.11 \pm 0.009$ & $0.17 \pm 0.006$ & $3.88 \mathrm{E}-12$ & $0.16 \pm 0.012$ & $0.21 \pm 0.007$ & $1.40 \mathrm{E}-03$ \\
\hline Rest latency (1 min) & $41.05 \pm 13.94$ & $125.91 \pm 16.01$ & $1.47 \mathrm{E}-03$ & & & & & & \\
\hline Adcyap1b & Wild type $(n=40)$ & Adcyap $1 b(n=39)$ & $p$ values & Wild type & Adcyap $1 b$ & $p$ values & Wild type & Adcyap $1 b$ & $p$ values \\
\hline Waking activity (s/waking min) & $4.02 \pm 0.266$ & $4.69 \pm 0.326$ & $1.14 \mathrm{E}-01$ & $1.35 \pm 0.091$ & $1.33 \pm 0.089$ & $9.30 \mathrm{E}-01$ & $.40 \pm 0.204$ & $3.82 \pm 0.252$ & $76 \mathrm{E}-01$ \\
\hline Rest (min/10 min) & $2.13 \pm 0.318$ & $1.18 \pm 0.246$ & $1.17 \mathrm{E}-02$ & $3.41 \pm 0.268$ & $3.01 \pm 0.287$ & 2.66E-01 & $2.51 \pm 0.251$ & $1.71 \pm 0.232$ & $1.93 \mathrm{E}-02$ \\
\hline Maximum amplitude/movement (pixels) & $7.70 \pm 0.141$ & $7.42 \pm 0.217$ & $4.39 \mathrm{E}-01$ & $7.54 \pm 0.161$ & $7.37 \pm 0.182$ & 7.17E-01 & $6.92 \pm 0.171$ & $6.87 \pm 0.200$ & 7.91E-01 \\
\hline Movement duration (s) & $0.15 \pm 0.002$ & $0.15 \pm 0.003$ & $9.22 \mathrm{E}-01$ & $0.20 \pm 0.003$ & $0.20 \pm 0.003$ & 5.83E-01 & $0.14 \pm 0.003$ & $0.14 \pm 0.003$ & $8.29 \mathrm{E}-01$ \\
\hline Movement frequency $(\mathrm{Hz})$ & $0.51 \pm 0.039$ & $0.64 \pm 0.043$ & $3.21 \mathrm{E}-02$ & $0.10 \pm 0.008$ & $0.11 \pm 0.009$ & 5.30E-01 & $0.43 \pm 0.031$ & $0.51 \pm 0.030$ & $8.09 \mathrm{E}-02$ \\
\hline Bout duration (s) & $1.22 \pm 0.091$ & $1.21 \pm 0.072$ & $6.73 \mathrm{E}-01$ & $0.35 \pm 0.009$ & $0.36 \pm 0.010$ & 4.10E-01 & $1.39 \pm 0.099$ & $1.48 \pm 0.097$ & 3.47E-01 \\
\hline Bout frequency (s) & $0.20 \pm 0.014$ & $0.24 \pm 0.013$ & $5.59 \mathrm{E}-02$ & $0.08 \pm 0.006$ & $0.08 \pm 0.007$ & $6.10 \mathrm{E}-01$ & $0.15 \pm 0.008$ & $0.16 \pm 0.008$ & $1.21 \mathrm{E}-01$ \\
\hline Rest latency (1 min) & $24.27 \pm 6.31$ & $26.65 \pm 5.03$ & $3.88 \mathrm{E}-01$ & & & & & & \\
\hline Cart & Wild type ( $n=48$ ) & $\operatorname{Cart}(n=33)$ & $p$ values & Wild type & Cart & $p$ values & Wild type & Cart & $p$ values \\
\hline laking acti & $4.08 \pm 0.300$ & $4.75 \pm 0.488$ & $1 \mathrm{E}-01$ & $0.83 \pm 0.042$ & $1.06 \pm 0.068$ & $\mathrm{OE}-02$ & $3.75 \pm 0.293$ & 272 & $85 \mathrm{E}-01$ \\
\hline Rest (m & $1.94 \pm 0.342$ & $2.48 \pm 0.453$ & $\mathrm{E}-01$ & $3.86 \pm 0.280$ & & $8.36 \mathrm{E}-02$ & $2.59 \pm 0.265$ & 328 & $9 \mathrm{E}-01$ \\
\hline Max amplitude/movement (pixels) & $7.40 \pm 0.249$ & $7.50 \pm 0.248$ & $9.69 \mathrm{E}-01$ & $6.91 \pm 0.217$ & $7.01 \pm 0.216$ & $9.85 \mathrm{E}-01$ & $7.01 \pm 0.248$ & $6.93 \pm 0.262$ & $8.33 \mathrm{E}-01$ \\
\hline Movement duration (s) & $0.16 \pm 0.004$ & $0.17 \pm 0.004$ & $2.82 \mathrm{E}-01$ & $0.19 \pm 0.004$ & $0.20 \pm 0.004$ & 2.41E-01 & $0.15 \pm 0.004$ & .004 & $8.55 \mathrm{E}-01$ \\
\hline Movement frequency $(\mathrm{Hz})$ & $0.51 \pm 0.034$ & & $5.97 \mathrm{E}-01$ & $0.07 \pm 0.005$ & & $6.34 \mathrm{E}-03$ & $0.43 \pm 0.033$ & 029 & $6.72 \mathrm{E}-01$ \\
\hline Bout duration (s) & $1.04 \pm 0.070$ & $1.61 \pm 0.179$ & $1.25 \mathrm{E}-02$ & $0.32 \pm 0.008$ & $0.36 \pm 0.042$ & 7.95E-01 & $1.29 \pm 0.086$ & $1.49 \pm 0.138$ & $3.61 \mathrm{E}-01$ \\
\hline Bout frequency (s) & $0.22 \pm 0.014$ & $0.19 \pm 0.017$ & $8.89 \mathrm{E}-02$ & $0.05 \pm 0.004$ & $0.07 \pm 0.004$ & $1.13 \mathrm{E}-02$ & $0.16 \pm 0.011$ & $0.14 \pm 0.012$ & $2.33 \mathrm{E}-01$ \\
\hline Rest latency (1 min) & $16.14 \pm 2.69$ & $24.81 \pm 3.63$ & $1.12 \mathrm{E}-02$ & & & & & & \\
\hline Cck & Wild type $(n=48)$ & $\operatorname{cck}(n=31)$ & $p$ values & Wild type & $C c k$ & $p$ values & Wild type & $C c k$ & $p$ values \\
\hline & 3.93 & 443 & $E-09$ & $0.96 \pm$ & & $\mathrm{E}-01$ & $2.08 \pm 0.12$ & & $2 \mathrm{E}-02$ \\
\hline Rest (min/ & $0.72 \pm 0$ & & -01 & $3.69 \pm 0.26$ & & $\mathrm{E}-01$ & $1.65 \pm 0.20$ & & $3 \mathrm{E}-01$ \\
\hline Maximum amplitude/movement (pixels) & $6.45 \pm 0.14$ & $6.40 \pm 0.204$ & $6.02 \mathrm{E}-01$ & $6.21 \pm 0.13$ & $6.25 \pm 0.18$ & $9.36 \mathrm{E}-01$ & $5.53 \pm 0.11$ & 15 & $3.45 \mathrm{E}-01$ \\
\hline Movement duration (s) & $0.16 \pm 0.00$ & $0.15 \pm 0.003$ & $4.91 \mathrm{E}-02$ & $0.20 \pm 0.00$ & $0.20 \pm 0.00$ & $7.56 \mathrm{E}-01$ & $0.14 \pm 0.00$ & $4 \pm 0.00$ & $2.28 \mathrm{E}-01$ \\
\hline Movement frequency $(\mathrm{Hz})$ & $0.55 \pm 0.03$ & $1.11 \pm 0.051$ & $5.90 \mathrm{E}-11$ & $0.08 \pm 0.01$ & $0.08 \pm 0.01$ & $6.81 \mathrm{E}-01$ & $0.32 \pm 0.02$ & & $9.76 \mathrm{E}-02$ \\
\hline Bout duration (s) & $1.12 \pm 0.06$ & $4.94 \pm 0.501$ & $1.09 \mathrm{E}-13$ & $0.34 \pm 0.01$ & $0.42 \pm 0.02$ & $6.18 \mathrm{E}-04$ & $0.80 \pm 0.03$ & $1.15 \pm 0.07$ & $2.48 \mathrm{E}-05$ \\
\hline Bout frequency (s) & $0.22 \pm 0.01$ & $0.13 \pm 0.007$ & $6.90 \mathrm{E}-09$ & $0.06 \pm 0.00$ & $0.06 \pm 0.01$ & $9.36 \mathrm{E}-01$ & $0.16 \pm 0.01$ & $0.15 \pm 0.01$ & 8.37E-01 \\
\hline Rest latency (1 min) & $20.48 \pm 3.61$ & $21.09 \pm 3.89$ & $4.48 \mathrm{E}-01$ & & & & & & \\
\hline Cgrp & Wild type $(n=42)$ & $\operatorname{Cgrp}(n=37)$ & $p$ values & Wild & Cgrp & alues & Wild & r & alues \\
\hline & $.26 \pm 0.26$ & & & $02 \pm$ & & & 9 & & \\
\hline Rest (min/10 min) & $0.89 \pm 0.16$ & $0.09 \pm 0.017$ & $3.62 \mathrm{E}-07$ & $2.98 \pm c$ & $1.69 \pm$ & $\mathrm{E}-04$ & $1.48 \pm$ & 19 & $\mathrm{E}-04$ \\
\hline Maximum amplitude/movement (pixels) & $7.20 \pm 0.15$ & $7.23 \pm 0.166$ & $8.06 \mathrm{E}-01$ & $6.82 \pm 0.13$ & $7.00 \pm 0.16$ & $3.46 \mathrm{E}-01$ & $6.21 \pm 0.12$ & 14 & $7.22 \mathrm{E}-02$ \\
\hline Movement duration (s) & $0.16 \pm 0.00$ & $0.16 \pm 0.002$ & $5.56 \mathrm{E}-01$ & $0.21 \pm 0.00$ & $0.22 \pm 0.00$ & $2.23 \mathrm{E}-01$ & $0.15 \pm 0.00$ & 00 & $5.67 \mathrm{E}-02$ \\
\hline Movement frequency $(\mathrm{Hz})$ & $0.55 \pm 0.04$ & $1.28 \pm 0.058$ & $3.50 \mathrm{E}-12$ & $0.07 \pm 0.01$ & $0.10 \pm 0.01$ & $5.27 \mathrm{E}-03$ & $0.36 \pm 0.03$ & 05 & $2.64 \mathrm{E}-03$ \\
\hline Bout duration (s) & $1.15 \pm 0.10$ & $5.40 \pm 0.759$ & $6.43 \mathrm{E}-11$ & $0.36 \pm 0.01$ & $0.37 \pm 0.01$ & $2.50 \mathrm{E}-01$ & $1.00 \pm 0.07$ & $1.47 \pm 0.17$ & $1.84 \mathrm{E}-02$ \\
\hline Bout frequency (s) & $0.22 \pm 0.01$ & $0.18 \pm 0.013$ & $3.14 \mathrm{E}-02$ & $0.06 \pm 0.00$ & $0.08 \pm 0.01$ & $1.01 \mathrm{E}-02$ & $0.15 \pm 0.01$ & $0.18 \pm 0.01$ & $2.38 \mathrm{E}-02$ \\
\hline Rest latency (1 min) & $17.84 \pm 3.11$ & $42.30 \pm 6.53$ & $9.60 \mathrm{E}-06$ & & & & & & \\
\hline Galanin & Wild type $(n=23)$ & Galanin $(n=57)$ & $p$ values & Wild type & Galanin & $p$ values & Wild type & Galanin & $p$ values \\
\hline $\min )$ & $.07 \pm 0.34$ & 2.52 & -09 & $1.64 \pm 0$ & 1.8 & -01 & $4.45 \pm$ & 3 & $\mathrm{E}-01$ \\
\hline Rest (min/10 min) & $0.96 \pm 0.36$ & $3.78 \pm 0.199$ & $7.25 \mathrm{E}-10$ & $2.22 \pm 0.30$ & \pm 0.21 & 7E-01 & $1.03 \pm 0.23$ & 5 & $9.32 \mathrm{E}-01$ \\
\hline Maximum amplitude/movement (pixels) & $7.50 \pm 0.18$ & $6.67 \pm 0.116$ & $5.62 \mathrm{E}-04$ & $6.02 \pm 0.24$ & $6.40 \pm 0.12$ & $9 \mathrm{E}-01$ & $7.84 \pm 0.12$ & 7.8 & $9.79 \mathrm{E}-01$ \\
\hline Movement duration (s) & $0.16 \pm 0.00$ & $0.15 \pm 0.002$ & $8.78 \mathrm{E}-03$ & $0.17 \pm 0.01$ & $0.18 \pm 0.00$ & $3 \mathrm{E}-02$ & $0.16 \pm$ & \pm & $8.69 \mathrm{E}-01$ \\
\hline Movement frequency $(\mathrm{Hz})$ & $0.72 \pm 0.05$ & $0.36 \pm 0.021$ & $1.25 \mathrm{E}-08$ & $0.21 \pm 0.02$ & $0.20 \pm 0.01$ & 7.14E-01 & $0.58 \pm 0.05$ & $0.55 \pm 0.03$ & 7.62E-01 \\
\hline Bout duration (s) & $1.21 \pm 0.10$ & $0.93 \pm 0.038$ & $2.97 \mathrm{E}-03$ & $0.43 \pm 0.01$ & $0.44 \pm 0.01$ & 9.70E-01 & $1.33 \pm 0.16$ & $1.24 \pm 0.07$ & 9.87E-01 \\
\hline Bout frequency (s) & $0.25 \pm 0.01$ & $0.15 \pm 0.006$ & $1.01 \mathrm{E}-09$ & $0.14 \pm 0.01$ & $0.13 \pm 0.01$ & 7.78E-01 & $0.20 \pm 0.01$ & $0.20 \pm 0.01$ & $8.52 \mathrm{E}-01$ \\
\hline Rest latency (1 min) & $27.62 \pm 7.03$ & $27.27 \pm 6.57$ & $7.50 \mathrm{E}-02$ & & & & & & \\
\hline Nociceptin & Wild type $(n=21)$ & Nociceptin $(n=57)$ & $p$ values & Wild type & Nociceptin & $p$ values & Wild type & Nociceptin & $p$ values \\
\hline /wakıng mın) & $4.06 \pm 0.38$ & $2.96 \pm 0.128$ & -02 & $0.96 \pm 0$ & $1.00 \pm 0.04$ & E-01 & 2.78 & & \\
\hline Rest (min/10 min) & $1.26 \pm 0.30$ & $1.84 \pm 0.155$ & $1.12 \mathrm{E}-02$ & $2.65 \pm 0.38$ & $3.26 \pm 0.20$ & $1.01 \mathrm{E}-01$ & $1.61 \pm 0.30$ & $1.78 \pm 0.17$ & 4.30E-01 \\
\hline Maximum amplitude/movement (pixels) & $7.40 \pm 0.34$ & $8.89 \pm 0.175$ & $2.93 \mathrm{E}-04$ & $6.92 \pm 0.26$ & $7.82 \pm 0.15$ & 4.14E-03 & $6.57 \pm 0.30$ & $7.65 \pm 0.15$ & $1.52 \mathrm{E}-03$ \\
\hline Movement duration (s) & $0.15 \pm 0.00$ & $0.17 \pm 0.003$ & $2.68 \mathrm{E}-04$ & $0.20 \pm 0.01$ & $0.22 \pm 0.00$ & 4.32E-02 & $0.15 \pm 0.00$ & $0.16 \pm 0.00$ & $4.69 \mathrm{E}-04$ \\
\hline Movement frequency $(\mathrm{Hz})$ & $0.55 \pm 0.05$ & $0.31 \pm 0.016$ & $7.95 \mathrm{E}-06$ & $0.08 \pm 0.01$ & $0.07 \pm 0.00$ & $2.26 \mathrm{E}-01$ & $0.35 \pm 0.03$ & $0.29 \pm 0.01$ & 4.93E-02 \\
\hline Bout duration (s) & $1.21 \pm 0.12$ & $0.81 \pm 0.029$ & $6.29 \mathrm{E}-04$ & $0.32 \pm 0.01$ & $0.36 \pm 0.01$ & $9.73 \mathrm{E}-03$ & $0.93 \pm 0.07$ & $0.88 \pm 0.04$ & $6.56 \mathrm{E}-01$ \\
\hline Bout frequency (s) & $0.21 \pm 0.02$ & $0.16 \pm 0.007$ & $8.38 \mathrm{E}-04$ & $0.07 \pm 0.01$ & $0.06 \pm 0.00$ & $1.51 E-01$ & $0.16 \pm 0.01$ & $0.14 \pm 0.01$ & 7.79E-02 \\
\hline Rest latency (1 min) & $20.25 \pm 5.72$ & $13.42 \pm 1.46$ & $5.77 \mathrm{E}-02$ & & & & & & \\
\hline
\end{tabular}


Table 3. Analysis of locomotor activity in transgenic larvae without heatshock

\begin{tabular}{|c|c|c|c|}
\hline \multirow[b]{2}{*}{ Hypocretin } & \multicolumn{3}{|l|}{ Day 5} \\
\hline & Wild type $(n=11)$ & Hypocretin $(n=19)$ & $p$ values \\
\hline Waking activity (s/waking min) & $3.54 \pm 0.544$ & $5.26 \pm 0.543$ & $3.69 \mathrm{E}-02$ \\
\hline Rest (min/10 min) & $3.10 \pm 0.911$ & $1.23 \pm 0.376$ & $7.39 \mathrm{E}-02$ \\
\hline Maximum amplitude/movement (pixels) & $11.60 \pm 3.322$ & $12.30 \pm 1.318$ & $2.20 \mathrm{E}-01$ \\
\hline Movement duration (s) & $0.14 \pm 0.007$ & $0.14 \pm 0.003$ & 4.01E-01 \\
\hline Movement frequency $(\mathrm{Hz})$ & $0.41 \pm 0.080$ & $0.61 \pm 0.062$ & $5.55 \mathrm{E}-02$ \\
\hline Bout duration (s) & $1.49 \pm 0.239$ & $1.59 \pm 0.125$ & $5.61 \mathrm{E}-01$ \\
\hline Bout frequency (s) & $0.16 \pm 0.035$ & $0.19 \pm 0.018$ & $5.19 \mathrm{E}-01$ \\
\hline Rest latency (1 min) & $11.07 \pm 1.25$ & $15.96 \pm 3.28$ & $8.13 \mathrm{E}-01$ \\
\hline Adcyap1b & Wild type $(n=21)$ & Adcyap $1 b(n=26)$ & $p$ values \\
\hline Waking activity (s/waking min) & $3.28 \pm 0.316$ & $2.93 \pm 0.239$ & $4.16 \mathrm{E}-01$ \\
\hline Rest (min/10 min) & $1.71 \pm 0.382$ & $2.71 \pm 0.426$ & $2.19 \mathrm{E}-01$ \\
\hline Maximum amplitude/movement (pixels) & $9.80 \pm 1.584$ & $9.58 \pm 1.618$ & $8.47 \mathrm{E}-01$ \\
\hline Movement duration (s) & $0.13 \pm 0.003$ & $0.13 \pm 0.003$ & $6.38 \mathrm{E}-01$ \\
\hline Movement frequency $(\mathrm{Hz})$ & $0.41 \pm 0.039$ & $0.36 \pm 0.032$ & $3.04 \mathrm{E}-01$ \\
\hline Bout duration (s) & $1.07 \pm 0.113$ & $1.05 \pm 0.108$ & $9.83 \mathrm{E}-01$ \\
\hline Bout frequency (s) & $0.19 \pm 0.019$ & $0.18 \pm 0.021$ & 4.94E-01 \\
\hline Rest latency (1 min) & $9.15 \pm 2.42$ & $8.16 \pm 0.98$ & $9.91 \mathrm{E}-01$ \\
\hline Cart & Wild type $(n=20)$ & $\operatorname{Cart}(n=26)$ & $p$ values \\
\hline ity $(s / w$ & $3.79 \pm 0.368$ & $3.38 \pm 0.358$ & $3.80 \mathrm{E}-01$ \\
\hline st $(\mathrm{min} / 10 \mathrm{mi}$ & $1.52 \pm 0.323$ & $1.93 \pm 0$ & $5.54 \mathrm{E}-01$ \\
\hline Maximum amplitude/movement (pixels) & $12.15 \pm 2.952$ & $11.68 \pm 3.197$ & $5.99 \mathrm{E}-01$ \\
\hline Movement duration (s) & $0.14 \pm 0.004$ & $0.14 \pm 0.005$ & $8.26 \mathrm{E}-01$ \\
\hline Movement frequency $(\mathrm{Hz})$ & $0.43 \pm 0.038$ & $0.38 \pm 0.046$ & $4.30 \mathrm{E}-01$ \\
\hline Bout duration (s) & $1.03 \pm 0.104$ & $0.99 \pm 0.077$ & $9.30 \mathrm{E}-01$ \\
\hline Bout frequency (s) & $0.19 \pm 0.020$ & $0.17 \pm 0.020$ & $5.99 \mathrm{E}-01$ \\
\hline Rest latency (1 min) & $38.32 \pm 14.55$ & $36.64 \pm 20.77$ & $7.09 \mathrm{E}-01$ \\
\hline Cck & Wild type $(n=29)$ & $C c k(n=17)$ & $p$ values \\
\hline Waking ac & $4.50 \pm 0.362$ & $3.90 \pm 0.257$ & 4.19E-01 \\
\hline Rest $(\min / 10 \mathrm{~min})$ & $1.26 \pm 0.261$ & $2.20 \pm$ & $9.60 \mathrm{E}-02$ \\
\hline Maximum amplitude/movement (pixels) & $13.29 \pm 2.039$ & $13.22 \pm 2.983$ & $9.73 \mathrm{E}-01$ \\
\hline Movement duration (s) & $0.15 \pm 0.003$ & $0.15 \pm 0.005$ & $6.41 \mathrm{E}-01$ \\
\hline Movement frequency $(\mathrm{Hz})$ & $0.49 \pm 0.041$ & $0.42 \pm 0.033$ & $3.57 \mathrm{E}-01$ \\
\hline Bout duration (s) & $1.60 \pm 0.241$ & $1.57 \pm 0.258$ & $9.73 \mathrm{E}-01$ \\
\hline Bout frequency (s) & $0.17 \pm 0.012$ & $0.16 \pm 0.018$ & $6.74 \mathrm{E}-01$ \\
\hline Rest latency (1 min) & $10.19 \pm 1.65$ & $13.96 \pm 3.13$ & 7.97E-02 \\
\hline Cgrp & Wild type ( $n$ & $\operatorname{Cgrp}(n$ & values \\
\hline Waking acti & $3.46 \pm 0.276$ & $4.12 \pm 0.278$ & $.56 \mathrm{E}-02$ \\
\hline Rest (min/ & $2.48 \pm 0.403$ & 37 & $7.54 \mathrm{E}-02$ \\
\hline Maximum amplitude/movement (pixels) & $11.00 \pm 1.680$ & $12.18 \pm 1.596$ & $1.11 \mathrm{E}-01$ \\
\hline Movement duration (s) & $0.14 \pm 0.003$ & $0.14 \pm 0.003$ & $1.96 \mathrm{E}-01$ \\
\hline Movement frequency $(\mathrm{Hz})$ & $0.40 \pm 0.035$ & $0.48 \pm 0.033$ & $3.77 \mathrm{E}-02$ \\
\hline Bout duration (s) & $1.32 \pm 0.138$ & $1.11 \pm 0.077$ & $6.95 \mathrm{E}-01$ \\
\hline Bout frequency (s) & $0.18 \pm 0.018$ & $0.22 \pm 0.016$ & $9.01 \mathrm{E}-02$ \\
\hline Rest latency (1 min) & $47.50 \pm 11.14$ & $45.03 \pm 9.52$ & $8.26 \mathrm{E}-01$ \\
\hline Galanin & Wild type $(n=19)$ & Galanin $(n=35)$ & $p$ values \\
\hline 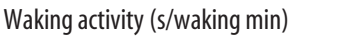 & 3.79 & $3.38 \pm 0.358$ & $3.80 \mathrm{E}-01$ \\
\hline Rest (min/ & $1.52=$ & 1.93 & $5.54 \mathrm{E}-01$ \\
\hline Maximum amplitude/moveme & $12.15 \pm 2.952$ & $11.68 \pm 3.197$ & $5.99 \mathrm{E}-01$ \\
\hline Movement duration (s) & $0.14 \pm 0.004$ & $0.14 \pm 0.005$ & $8.26 \mathrm{E}-01$ \\
\hline Movement frequency $(\mathrm{Hz})$ & $0.43 \pm 0.038$ & $0.38 \pm 0.046$ & $4.30 \mathrm{E}-01$ \\
\hline Bout duration (s) & $1.03 \pm 0.104$ & $0.99 \pm 0.077$ & $9.30 \mathrm{E}-01$ \\
\hline Bout frequency (s) & $0.19 \pm 0.020$ & $0.17 \pm 0.020$ & $5.99 \mathrm{E}-01$ \\
\hline Rest latency (1 min) & $9.20 \pm 0.76$ & $11.66 \pm 1.86$ & $5.86 \mathrm{E}-01$ \\
\hline Nociceptin & Wild type $(n=44)$ & Nociceptin $(n=44)$ & \\
\hline & $2.97=$ & 2.78 & $6.22 \mathrm{E}-01$ \\
\hline Rest $(\mathrm{min} / 10 \mathrm{mi}$ & $2.83 \pm 0.388$ & $3.69 \pm 0.323$ & $4.01 \mathrm{E}-02$ \\
\hline Maximum amplitude/r & $9.57 \pm 1.344$ & $9.74 \pm 1.146$ & 4.53E-01 \\
\hline Movement duration (s) & $0.14 \pm 0.003$ & $0.14 \pm 0.003$ & $1.76 \mathrm{E}-01$ \\
\hline
\end{tabular}

Table 3. Continued

\begin{tabular}{llll}
\hline & \multicolumn{3}{l}{ Day 5} \\
\cline { 2 - 4 } Nociceptin & Wild type $(n=11)$ & Hypocretin $(n=19)$ & $p$ values \\
\hline Movement frequency $(\mathrm{Hz})$ & $0.33 \pm 0.031$ & $0.27 \pm 0.026$ & $1.56 \mathrm{E}-01$ \\
Bout duration $(\mathrm{s})$ & $0.94 \pm 0.074$ & $1.23 \pm 0.097$ & $1.12 \mathrm{E}-02$ \\
Bout frequency $(\mathrm{s})$ & $0.17 \pm 0.015$ & $0.12 \pm 0.012$ & $1.41 \mathrm{E}-02$ \\
Rest latency $(1 \mathrm{~min})$ & $6.40 \pm 0.44$ & $6.24 \pm 0.42$ & $6.89 \mathrm{E}-01$ \\
\hline
\end{tabular}

Values are mean \pm SEM $p$ values from Kruskall-Wallis one-way ANOVA. Larvae with the HS-nociceptin transgene exhibited decreases in measures of spontaneous locomotion independent of heatshock, but these decreases were not statistically significant after correction for multiple comparisons.

age locomotor parameters across the duration of the experiment were selected for display.

Analysis of sensory responsiveness. On day five of development $(\sim 124$ hpf), larvae of either sex were distributed into single wells of a 96-well plate (7701-1651; Whatman), allowing simultaneous tracking of each individual. Locomotor activity was monitored via a videotracking system using a camera with $1392 \times 1040$-pixel resolution running at $15 \mathrm{~Hz}$ (Scout sca1400-30fm, Basler Vision Technologies). Stimulus delivery and quantification of larval motion were performed in Matlab. For both the dark-flash and the tap experiments, stimulus ranges were tested upon wild-type larvae, and the apparatus was set to deliver a range of stimuli that reliably elicited a range of responses, from undetectable (no difference from baseline motion) to saturating (no increase of response probability with stimuli of greater strength).

For dark-flash experiments, larvae were heatshocked at $37^{\circ} \mathrm{C}$ from 9:30 to 10:30 P.M. of $5 \mathrm{dpf}(\sim 131.5-132.5 \mathrm{hpf})$. Beginning at 11 P.M., larvae were subjected to randomized reductions in white light intensity, from a slight dimming to almost complete darkness. Stimuli were delivered by computer-controlled changes in voltage delivered to a custom-built array of 48 white LEDs. These dark flashes lasted for $10 \mathrm{~s}$ and occurred at $60 \mathrm{~s}$ intervals for $4 \mathrm{~h}$. For tap experiments, larvae were heatshocked at $37^{\circ} \mathrm{C}$ from 9:30 to 10:30 P.M. of $5 \mathrm{dpf}(\sim 131.5-132.5 \mathrm{hpf})$. Stimuli were delivered by computer-controlled increases in voltage to a solenoid (Allied Electronics 24-I-12D) attached to the apparatus. Beginning at 3:15 A.M. and continuing for $4 \mathrm{~h}$, the dish containing larvae was subjected to automated mechanical taps of randomized intensities. These taps occurred at 30 s intervals. The timing of stimulus delivery ( $\geq 30$ s between each stimulus) has been shown to be sufficient to prevent behavioral habituation to repetitive stimuli (Burgess and Granato, 2007a). No declines in responsiveness were observed across the duration of the experiments.

For the dark-flash and tap stimuli, a larva was scored as responding if it displaced $>10$ pixels within a brief time period following the stimulus ( $3 \mathrm{~s}$ for dark flashes, $0.6 \mathrm{~s}$ for taps). Responses of each larva were averaged over 40 replicates of each stimulus intensity for dark flashes, and 45 replicates of each stimulus intensity for taps.

For the heat stimulus experiments, larvae were heatshocked from 8 to 9 A.M. on $6 \mathrm{dpf}(\sim 142-143 \mathrm{hpf})$. One hour after the completion of this heatshock ( $\sim 144 \mathrm{hpf})$, the response of the larvae to a $5 \mathrm{~min}$ pulse of warm $\left(37^{\circ} \mathrm{C}\right)$ water was recorded.

Correction for background locomotor activity. To generalize our tests of sensory responsiveness independent of circadian time, we corrected our measurements for differences in basal locomotor activity. The background probability of motion was calculated by determining the number of larvae that displaced $>10$ pixels within the appropriate time interval after a "sham" stimulus, which was $15 \mathrm{~s}$ before each light stimulus or $5 \mathrm{~s}$ before each tap stimulus. These background movement data (320 replicates for lights, 540 for taps) were used to calculate an offset value for each larva that estimated its average basal probability of movement any point in time. By subtracting this background probability of motion, the maximum probability of response (i.e., the level at which responses were asymptotic and did not increase with stimuli of greater strength) was lowered. To correct for this decrease and thus to represent the full range of response in an averaged population (0 to maximal probability of response), we divided by (maximum response minus background offset), which restored the maximum response to its original, asymptotic level. 
Thus, for each stimulus level, the probability of response at a given stimulus intensity was calculated via the following equation:

corrected $\mathrm{P}($ response $)$ observed value

$$
\times \frac{\text { [observed value }- \text { background offset }]}{[\text { max observed value }- \text { background offset }]}
$$

The maximum response probability was calculated in each experiment for each genotype (transgenic and wild-type siblings) by determining the average number of individuals that responded to the two strongest stimuli over the many replicates of these stimuli.

Distributions for response latency were obtained by measuring the elapsed time between stimulus and response at the two highest stimulus levels. In our latency measurements, we normalized for background differences in basal movement frequency by expressing latency in terms of the following ratio:

corrected latency $=$

Time to first movement observed after a stimulus

Time to first movement observed, independent of a stimulus

Response threshold was calculated by fitting a sigmoid curve to the corrected response data, and determining the stimulus level at which half of the maximum response was reached. Distributions for response threshold were generated by determining the range of threshold values derived from fitting sigmoid curves to 200 bootstrap replicates for each genotype.

For the responses to heat pulse, the average activity (pixels per second) for each genotype was obtained for a $5 \mathrm{~min}$ period before stimulus delivery, and was subtracted from the observed values during the analysis window.

Principal components analysis and phenotypic clustering. Data were aggregated for 17 behavioral measures (waking activity, rest bouts, movement amplitude, movement duration, movement frequency, bout duration, bout frequency, rest latency, tap latency, tap response, tap threshold, dark latency, dark response, dark threshold, heat maximum, heat response, heat recovery) and seven peptides (hypocretin, adcyap $1 b$, cart, cck, cgrp, galanin, and nociceptin). Each data point was defined as the ratio of the response of transgenic animals to the response of their wild-type siblings. The data were then log-transformed to ensure that both positive and negative ratiometric values were numerically equivalent, and $z$-transformed (for each peptide) to place all peptides on a common scale. Phenotypic profiles for the 17 behavioral measures were clustered by similarity in Matlab.

The dataset was then subject to a singular value decomposition to identify the eigenvectors and their corresponding eigenvalues. The generality of the resulting space was evaluated in two ways. First, a jackknife analysis of the data was performed, decomposing a dataset comprising each possible subset of six peptides. Next, to construct a null dataset, a matrix consisting of our dataset was decomposed after it had been randomly shuffled; this analysis was repeated 10,000 times to define the relevant distributions of possible eigenvector values. The eigenvectors and projections from the jackknife analysis were compared with those generated from the full dataset, and against those generated from random data.

\section{Results}

\section{Analysis of spontaneous locomotor behaviors}

Animals in an increased state of arousal have been proposed to exhibit increased spontaneous locomotor activity and increased sensory responsiveness (Pfaff, 2006). To analyze spontaneous locomotor activity in larval zebrafish, we quantified locomotor behaviors via a videotracking assay (Prober et al., 2006). As previously reported (Prober et al., 2006; Rihel et al., 2010), larval zebrafish after $5 \mathrm{dpf}$ (120 hpf) exhibit robust differences in locomotor behavior between day and night (Fig. 1A). Fish were especially active during the day (Table 1, Fig. $1 A$ ); in contrast, periods of rest were increased at night (Table 1).

Although these analyses are suitable for distinguishing overt behavioral differences, they do not completely describe the un-
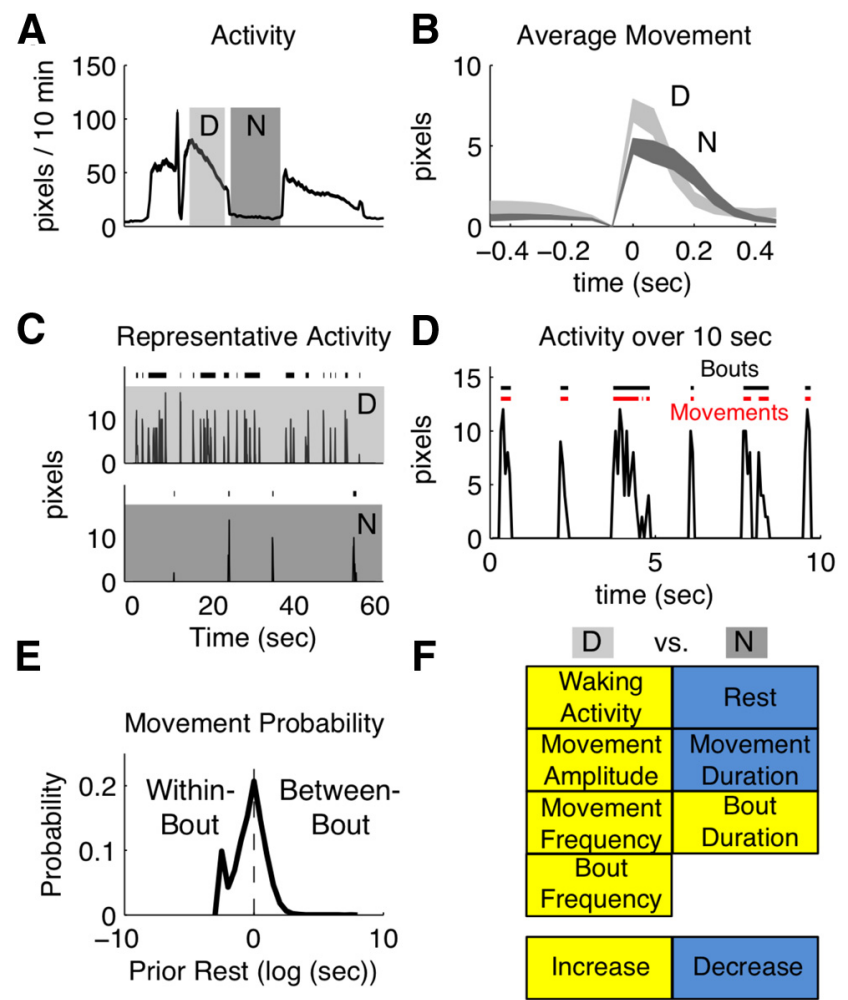

Figure 1. Definitive parameters of spontaneous locomotion in zebrafish larvae. $\boldsymbol{A}$, Mean activity plot for 80 larvae between 5 and $6 \mathrm{dpf}$ ( 119-157 hpf). Light and dark boxes represent the period of time during which locomotor activity is analyzed ( $D$, day $5 ; \mathrm{N}$, night 5 ). The sharp increase and decrease in activity immediately before the first box represents the effect of a $1 \mathrm{~h}$ heatshock at $37^{\circ} \mathrm{C}$. Each data point represents the number of pixels displaced in a $10 \mathrm{~min}$ time window, and the width of the line represents \pm SEM. $\boldsymbol{B}$, Traces showing average profiles of individual movements, measured by pixel displacement at $15 \mathrm{~Hz}$ resolution during day (light shading) and night (dark shading). The extent of shading represents \pm SD. Daytime movements are $\sim 25 \%$ larger in amplitude $\left(p<1 \times 10^{-16}\right)$, and $\sim 5 \%$ shorter in duration ( $p=$ $\left.6 \times 10^{-4}\right)$. C, Traces showing statistically typical patterns of activity over $60 \mathrm{~s}$ for day (light shading) and night (dark shading). Average values were compiled for five parameters of locomotor behavior (movement amplitude, movement duration, movement frequency, bout duration, bout frequency) during each period of analysis. These parameters were used in a search among all larvae to find the best fitting 1 min window of locomotor activity. Movement bouts are indicated by horizontal black lines above each activity trace. Movement frequency was $\sim 7$ times higher during the day $\left(p<1 \times 10^{-16}\right)$; movement bouts were $\sim 3$ times longer $(p<$ $\left.1 \times 10^{-16}\right)$ and $\sim 3$ times more frequent $\left(p<1 \times 10^{-16}\right)$ during the day. $\boldsymbol{D}$, Movements are clustered into bouts. The activity of a single larva is shown by measuring pixel displacement sampled at $15 \mathrm{~Hz}$ over $10 \mathrm{~s}$. Individual movements (separated by $\leq 67 \mathrm{~ms}$ ) are indicated by red lines above the activity trace, while clustered movements (separated by $\leq 1 \mathrm{~s}$ ) are grouped into bouts of motion and delineated by black lines above the plot. $\boldsymbol{E}$, The most common interval between movement initiation is $1 \mathrm{~s}$, as shown by comparing probability of movement with time elapsed since the last movement, using data underlying the day 5 locomotion shown in $\boldsymbol{A}$. $\boldsymbol{F}$, Summary of statistical comparisons between day 5 and night 5 locomotor data. Statistically significant increases are shown in yellow, while statistically significant decreases are shown in blue. See Table 1 for $p$ values. Significance thresholds at the 0.05 level were corrected for multiple comparisons with the Holm-Bonferroni method.

derlying differences in locomotor activity. For example, they do not answer the following questions: do differences in activity result from changes in the strength or frequency of individual movements, in the organization of individual movements into contiguous bouts, or some combination of these parameters? To address these questions, we sampled locomotor activity at a resolution of $15 \mathrm{~Hz}$ (Table 1), allowing us to quantify movement frequency (the number of times a movement was initiated per second), movement duration (the average length of individual movements before returning to rest), and movement amplitude 


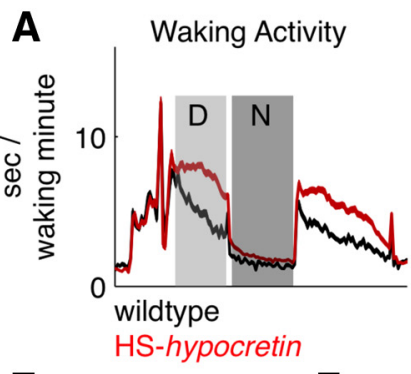

E

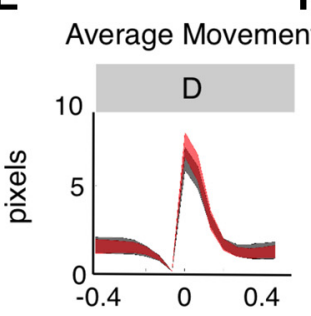

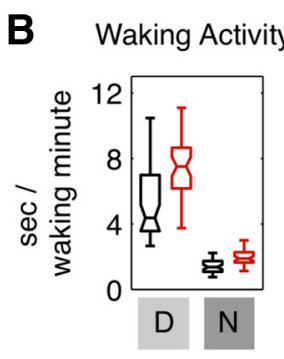

G
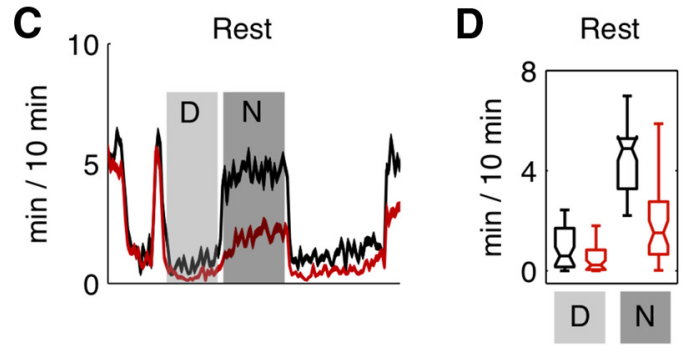

H N

Representative Activity

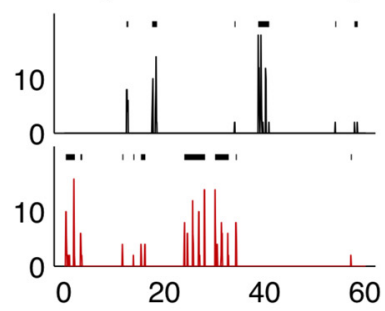

Representative Activity

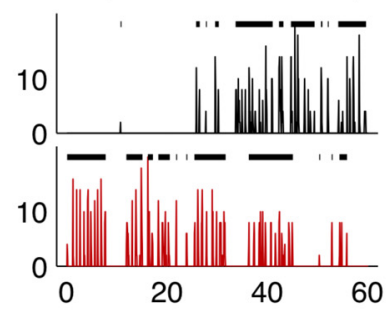

I

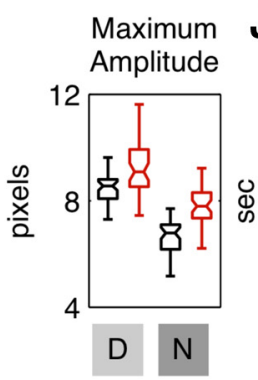

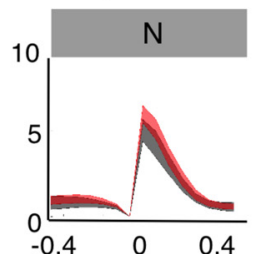

J Movement $\mathbf{K}$ Movement

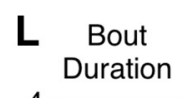

M
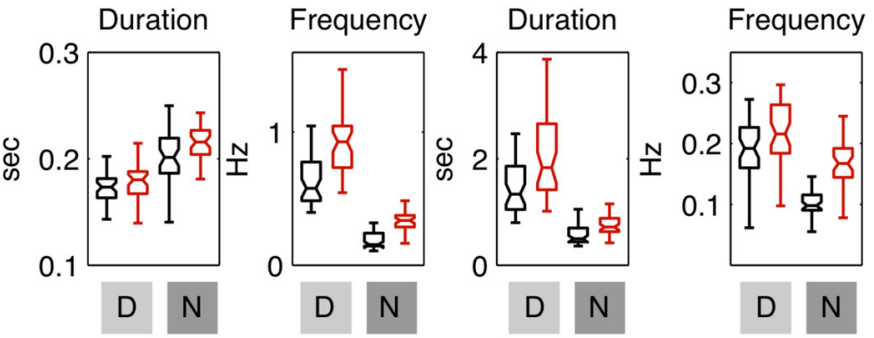

\begin{tabular}{|c|c|}
\hline $\begin{array}{c}\text { Waking } \\
\text { Activity }\end{array}$ & Rest \\
\hline $\begin{array}{c}\text { Movement } \\
\text { Amplitude }\end{array}$ & $\begin{array}{c}\text { Movement } \\
\text { Duration }\end{array}$ \\
\hline Movement & Bout \\
Frequency & Duration \\
\hline Bout & Rest \\
Frequency & Latency \\
\hline
\end{tabular}

Figure 2. Effects of hypocretin on locomotor activity. $\boldsymbol{A}-\boldsymbol{D}$, Mean waking activity $(\boldsymbol{A})$ and rest bout $(\boldsymbol{C})$ plots and quantitative comparisons $(\boldsymbol{B}, \boldsymbol{D})$ for larvae between 5 and $6 \mathrm{dpf}$. Light and dark shading represents the period of time during which locomotor activity is analyzed (D, day $5 ; \mathrm{N}$, night 5 ). Hypocretin (red) induced striking increases in waking activity $(\boldsymbol{A}, \boldsymbol{B})$ and decreases in rest bouts $(\boldsymbol{C}, \boldsymbol{D})$, compared with wild-type siblings (black). For the box-and-whisker plots in $\boldsymbol{C}, \boldsymbol{D}$, and $\boldsymbol{I}-\boldsymbol{M}$, the analysis timeframe is indicated by light and dark shading as in $(\boldsymbol{A})$, the horizontal lines show the medians, the notches correspond to the $95 \%$ confidence intervals around the medians, the open regions delineate the 25 th and 75 th quartiles, and the lines represent the most extreme data points within the distribution. $\boldsymbol{E}, \boldsymbol{F}$, Average single movement traces are shown for day $(\boldsymbol{E})$ and night $(\boldsymbol{F})$, comparing hypocretin-overexpressing larvae (red) with their wild-type siblings (black). $\boldsymbol{G}, \boldsymbol{H}$, Traces showing statistically typical patterns of activity over $60 \mathrm{~s}$ for day $(\boldsymbol{G})$ and night $(\boldsymbol{H}) . \boldsymbol{I}-\mathbf{M}$, Comparisons of locomotor parameters between hypocretin-overexpressing larvae (red) with their wild-type siblings (black). The most striking differences were in the frequency of movement initiation: hypocretin induced a $\sim 40 \%$ increase in movement frequency during the day $\left(p=4 \times 10^{-4}\right.$ ) and a $\sim 70 \%$ increase at night $\left(p=8 \times 10^{-12}\right)$. $\mathrm{N}$, Summary of statistical comparisons for locomotor data during the day. Statistically significant increases hypocretin larvae are shown in yellow, while statistically significant decreases are shown in blue. See Table 2 for $p$ values. Significance thresholds at the 0.05 level were corrected for multiple comparisons with the Holm-Bonferroni method.

(the maximum number of pixels displaced per movement). Traces indicating average activity profiles of wild-type larvae were generated for day and night movement beginning in the afternoon (2 to 11 P.M.) of $5 \mathrm{dpf}(\sim 124-133 \mathrm{hpf})$, and during the following night (Fig. $1 A, B$ ). In general, daytime movements occurred much more frequently, were of slightly higher amplitude, and were of shorter duration than nighttime movements (Fig. $1 B, C$,F; Fig. 2I-K, wild type; Table 1 ). Thus, much of the day versus night differences in locomotor activity is driven by the frequency of movement initiation, with only slight changes in the kinematic properties of individual movements.

To distinguish whether the increase in average movement duration at night reflected a genuine circadian influence on locomotion or was an epiphenomenon of nighttime darkness, we repeated the analysis under constant dark and constant light conditions after circadian entrainment (Table 1). Both movement amplitude and movement frequency recapitulated the pattern observed under normal light-dark cycling, with higher activity levels during circadian day. The day-night differences in movement frequency were attenuated in both constant dark and constant light treatments compared with normal light cycling conditions, and we observed a reduction in movement amplitude during circadian night in both constant dark and constant light conditions. Our analysis of movement duration, however, indicated that longer movements were observed in constant dark and shorter movements in constant light, regardless of circadian time (Table 1). Together, these data suggest that differences in movement frequency and amplitude arise from circadian influences, whereas the difference in movement duration reflects a circadianindependent feature of movement in darkness.

To examine the architectural structure of locomotion, we determined how individual movements are clustered into bouts of activity. Qualitative analysis of activity traces of individual larvae indicated that some movements are isolated, whereas other movements are organized in bouts of movements in rapid sequence (Fig. 1D). A plot of elapsed rest versus the probability of motion of individual larvae during day 5 revealed that larvae have the highest probability of motion following a rest interval of $\sim 1 \mathrm{~s}$ (Fig. 1E). We thus chose $1 \mathrm{~s}$ to delineate the boundary between movement bouts, and thereby defined a movement bout as a continuous group of movements interrupted by $\leq 1 \mathrm{~s}$ of rest. As with the frequency of individual movements, the frequency of movement bout initiation was increased greatly during the day. In addition, bout duration was much greater during day than 
night (Fig. $1 C$; Fig. $2 L, M$, wild type; Table 1 ). Thus, once a larva initiated a movement, it tended to remain active for a longer period of time during the daytime compared with night. Together, our high-resolution analysis enabled us to represent complex spontaneous locomotor behaviors by five simple parameters: movement frequency, movement duration, movement amplitude, bout frequency, and bout duration.

To test the potential of our high-resolution analysis in detecting neuropeptide-induced behavioral changes, we focused on hypocretin (also known as orexin). Previous work showed that induction of hypocretin expression in stable transgenic larvae stimulates activity and reduces rest (Prober et al., 2006; Fig. $2 A-D$; Table 2), but these analyses could not determine which aspect(s) of individual movements were responsible for the differences in overall locomotor activity. On $5 \mathrm{dpf}$, expression of hypocretin slightly increased the average maximum movement amplitude (Fig. 2E, I,N; Table 2). The increase in movement frequency (Fig. $2 G, K, N$ ) was much more pronounced, as were increases in movement bout frequency (Fig. 2G, $M, N$ ) and duration (Fig. $2 G, L, N)$. Similar increases for all of these parameters were observed on the following night (Fig. 2I-M; Table 2). Increases in all measured parameters extended similarly through $6 \mathrm{dpf}$ (Table 2). Thus, hypocretin greatly increased the frequency of movement initiation and the length of movement bouts, with minimal effects on the amplitude and duration of individual movements. This analysis highlights the power of our high-resolution assays to uncover differences in spontaneous locomotor activity and to elucidate neuropeptidergic effects upon these behaviors.

\section{Analysis of sensory responsiveness}

An animal in an elevated arousal state should exhibit, in addition to increases in spontaneous locomotor activity, increased responsiveness to sensory stimuli of multiple modalities (Pfaff, 2006). To analyze sensory responsiveness, we equipped our videotracking apparatus with computer-controlled delivery of diverse stimuli. This novel paradigm facilitated delivery of changes in light, sound, and temperature in parallel to multiple larvae, and enabled collection of locomotor response data in real time (Fig. 3A-D).

Previous work indicated that sudden onset of darkness induces robust locomotor responses in zebrafish larvae (Prober et al., 2006; Burgess and Granato, 2007b). We found that the magnitude of these responses correlated with the strength of the stimulus (Fig. 3A), where a weak stimulus consisted of a slight dimming of ambient light and a strong stimulus was a transition to almost complete darkness. Varying the strength of such "darkflash" stimuli produced a sigmoidal response curve, with asymptotes at the basal level of locomotion with weak or no stimuli and the maximal level of response at the strongest stimuli (Fig. $3 A, C, E)$. Similarly, responses to automated taps of various intensities (from inaudible to asymptotic) were collected and analyzed in a manner analogous to the dark flashes (Fig. $3 B, C, F$ ). To analyze the response to a thermal stimulus, we briefly exposed the larvae to warm $\left(\sim 37^{\circ} \mathrm{C}\right)$ water and assessed changes in locomotor activity (Prober et al., 2008; Fig. 3D, G).

We established nine individual components of responsiveness of larval zebrafish to sensory stimuli. From both the dark-flash and tap analyses, we extracted three parameters of response behaviors: (1) probability (the maximal response observed in terms of percentage of larvae responding; Fig. 3C), (2) threshold (the stimulus strength sufficient to induce a response at half of its maximal value; Fig. 3C), and (3) latency (the time elapsed between a stimulus and the first observed movement). From the
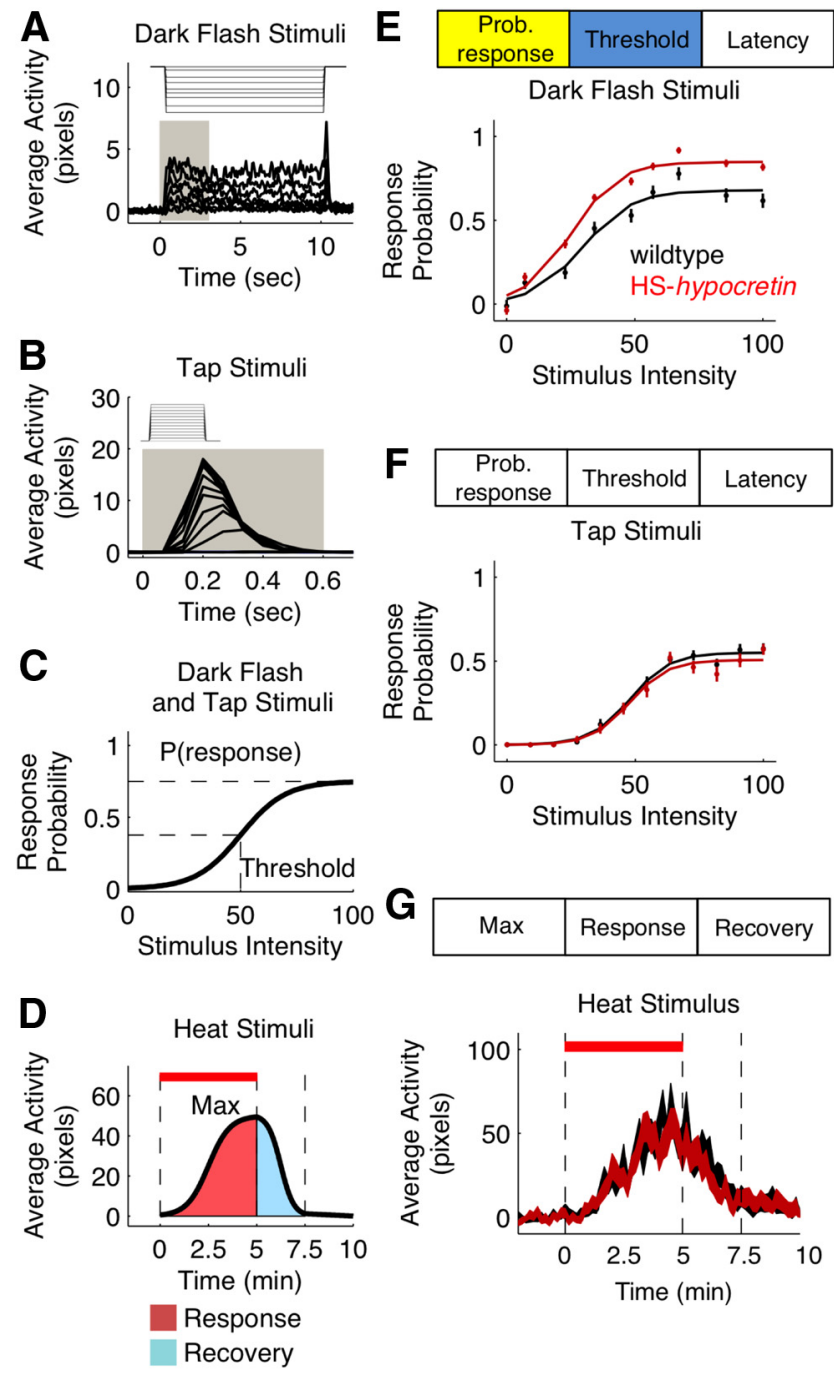

Figure 3. Effects of hypocretin on sensory responsiveness. $A, B$, Overview of the dark-flash and tap stimulus paradigms. $\boldsymbol{A}, \boldsymbol{B}$, Average locomotor responses of 96 wild-type larvae at $5 \mathrm{dpf}$ $[\sim 133-137$ hpf for dark flashes $(\boldsymbol{A}), \sim 137.25-141.25 \mathrm{hpf}$ for taps $(\boldsymbol{B})]$ to stimuli of varying intensity are shown. $C$, Response curves are generated via analysis of the locomotor data from $\boldsymbol{A}$ and $\boldsymbol{B}$ within a brief period of time following the stimuli $(\boldsymbol{A}, \boldsymbol{B}$, gray boxes; $3 \mathrm{~s}$ following dark flashes, and $0.6 \mathrm{~s}$ following the taps). Three response parameters are calculated: (1) responsiveness, or the maximum probability of response at the strongest stimuli; (2) threshold, or the stimulus strength at which the half-maximal response is reached; and (3) response latency, or the average time elapsed between the stimulus and initiation of activity. D, Overview of the thermal stimulus paradigm. A 5 min heat pulse is delivered to larvae on $6 \mathrm{dpf}$ ( $\sim 144 \mathrm{hpf}$ ). Three behavioral parameters are recorded for each larva: (1) the maximal activity during the heat exposure, measured in pixels displaced per second; (2) the total response, measured in total pixels displaced during the heat exposure; and (3) the recovery, measured in total pixels displaced during the $2 \mathrm{~min}$ following heat exposure. $\boldsymbol{E}-\mathbf{G}$, Response of hypocretin-overexpressing larvae to sensory stimuli. Statistical comparisons are summarized as in Figures 1 and 2. Compared with their wild-type siblings, hypocretin-overexpressing larvae showed no change in response latency to dark-flash stimuli $(\boldsymbol{E})$, but a striking increase in probability of response $(p=$ $\left.6.6 \times 10^{-11}\right)$ and a decrease in response threshold $\left(p=1.7 \times 10^{-4}\right)$. In contrast, hypocretin-overexpressing larvae showed no changes in response to tap $(\boldsymbol{F})$ or thermal $(\boldsymbol{G})$ stimuli. Width of the line in $\mathbf{G}$ represents \pm SEM. See Table 4 for statistical comparisons. Significance thresholds at the 0.05 level were corrected for multiple comparisons with the HolmBonferroni method.

heat-response analyses, we extracted three parameters: (1) maximal magnitude of response, (2) total locomotor activity exhibited over the course of stimulus application, and (3) total activity exhibited during the recovery period as temperature returned to normal (Fig. 3D). 
cck
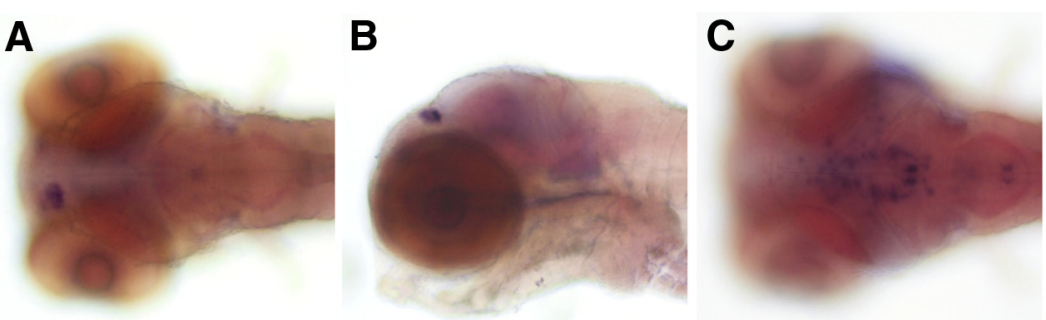

D
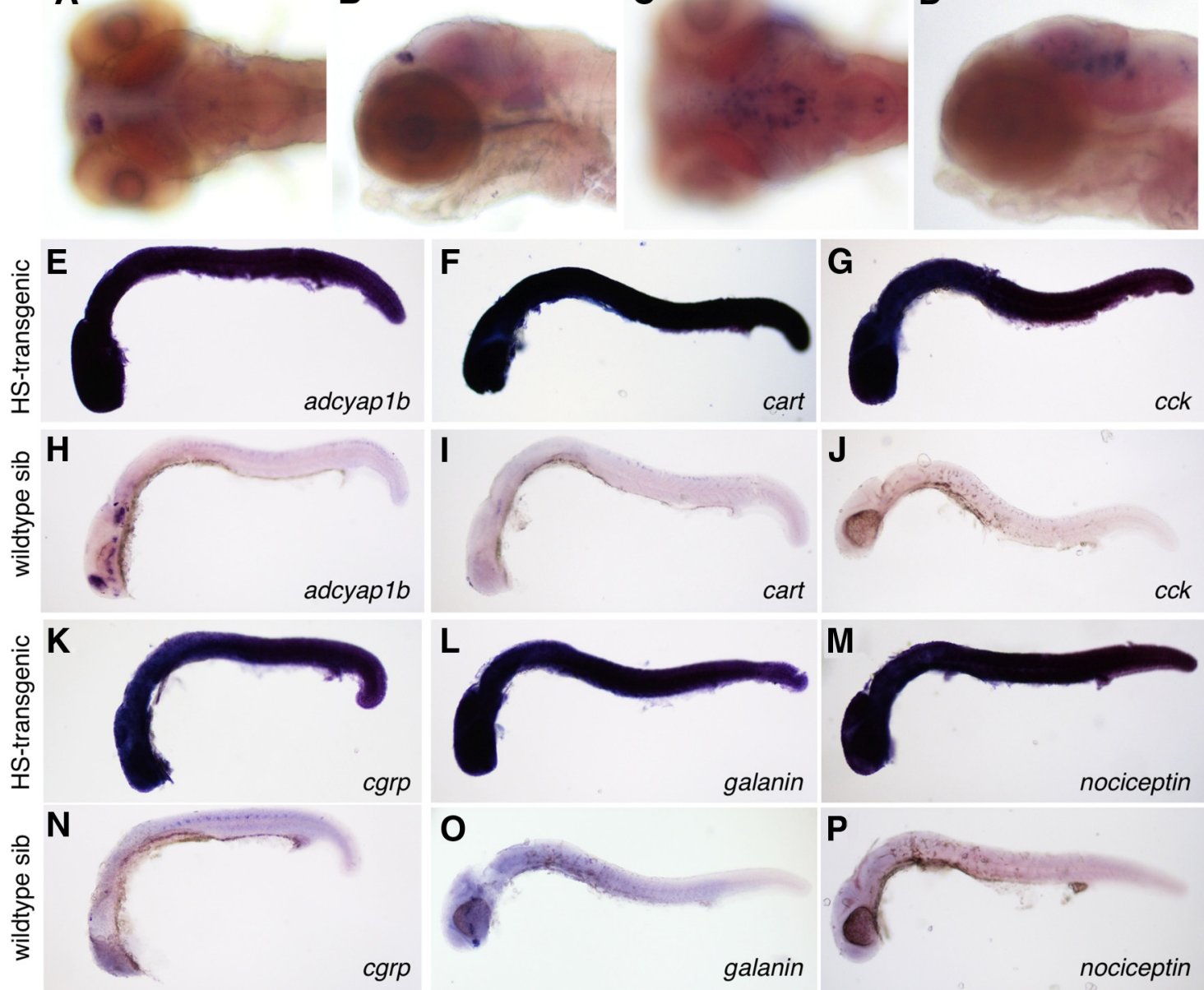

Figure 4. Expression of $c c k$ and nociceptin at $5 \mathrm{dpf}$, and ubiquitous induction of peptide expression by heatshock. $\boldsymbol{A}-\boldsymbol{D}$, Expression of the indicated transcripts via in situ hybridization analysis, viewed dorsally $(\boldsymbol{A}, \boldsymbol{C})$ and laterally $(\boldsymbol{B}, \boldsymbol{D})$ at $5 \mathrm{dpf}$. Cck $(\boldsymbol{A}, \boldsymbol{B})$ was expressed prominently in the left habenula, while nociceptin $(\boldsymbol{C}, \boldsymbol{D})$ was expressed in clusters of cells localized symmetrically within the brain. $\boldsymbol{E}-\boldsymbol{P}$, Expression of indicated transcripts in transgenic embryos and their wild-type siblings at $1 \mathrm{dpf}$. Embryos were heatshocked for $1 \mathrm{~h}$ at $37^{\circ} \mathrm{C}$, and were fixed $2 \mathrm{~h}$ postheatshock for in situ hybridization. Upon heatshock, peptide expression was induced ubiquitously in transgenic embryos, but not in their wild-type siblings.

To test the potential of our high-resolution analysis in detecting neuropeptide-induced changes in sensory responsiveness, we exposed heatshock (HS)-hypocretin larvae and their wild-type siblings to dark-flash, mechanoacoustic, and thermal stimuli. Because hypocretin induces changes in basal movement frequency (Fig. 2), we corrected our sensory responsiveness measurements for background differences in movement probability (see Materials and Methods). Consequently, in our responsiveness experiments, we report the probability that an observed movement resulted from the stimulus, independent from any differences in basal locomotor activity. Even after these corrections, HShypocretin larvae exhibited strikingly increased overall responsiveness to the dark-flash stimuli, and a concomitant decrease in the response threshold (Fig. $3 E$ ). In contrast, the responsiveness of HS-hypocretin larvae to acoustic and thermal stimuli was indistinguishable from that of their wild-type siblings (Fig. $3 F, G$ ). Thus, although hypocretin strongly elevated behaviors associated with sensory responsiveness, its effects were surprisingly modality-specific, demonstrating that characteristics of responsiveness to diverse stimuli can clearly be independent in larval zebrafish. This analysis illustrates the power of our assay to uncover subtle differences in behaviors associated with sensory re- sponsiveness, and to elucidate neuropeptidergic effects on these behaviors.

\section{Systematic comparison of neuropeptidergic regulation of arousal}

To determine whether the partitioning of arousal behaviors observed upon hypocretin expression can be extended to other neuropeptides, we created stable transgenic zebrafish in which candidate neuropeptides could be inducibly expressed upon heatshock (Fig. 4). We reasoned that this approach would facilitate systematic dissection of arousal behaviors and suggest the evolutionarily conserved functions of molecular regulators of arousal. Peptides were selected to maximize diversity with respect to peptide family and roles in arousal-related behaviors, and to sample peptides known to be expressed within the CNS of zebrafish larvae within the first $5 \mathrm{dpf}$ (Alt et al., 2006; Blechman et al., 2007; Nishio et al., 2012; Podlasz et al., 2012; Fig. 4A-D). Based on these criteria, we chose peptides suggested from mammalian studies to promote sleep (galanin), induce (cck, cart, adcyap $1 b$ ) or alleviate anxiety (nociceptin), regulate locomotor activity (adcyap 1b, cgrp), or modulate stress (adcyap1b) for further analyses (Crawley and Corwin, 1994; Jenck et al., 1997; 
Köster et al., 1999; Kovács et al., 1999; Hashimoto et al., 2001; Reinscheid and Civelli, 2002; Saper et al., 2005; Gavioli et al., 2007; Rogge et al., 2008; Hammack et al., 2009; Schorscher-Petcu et al., 2009; Vaudry et al., 2009; Rotzinger et al., 2010; Ressler et al., 2011; Sink et al., 2011). We studied the effects of neuropeptide expression on arousal behaviors in zebrafish larvae (Figs. 5-9; Tables 2-5).

We chose a gain-of-function approach for three reasons. First, classic studies of neuropeptide function have established the power of gain-of-function assays to characterize neuropeptidergic activities via injection of purified neuropeptide into the brain and analysis of resulting behaviors (Pedersen and Prange, 1979; Södersten et al., 1983; Clark et al., 1984; Sakurai et al., 1998; Nakazato et al., 2001). In this approach, the neuropeptide is expressed at levels sufficient to occupy and activate most if not all its receptors, resulting in a gain-of-function phenotype independent of the site of neuropeptide expression. Although such approaches cannot distinguish between direct and indirect effects, gain-of-function assays have led to the isolation and characterization of signals that regulate specific behaviors in vertebrates (e.g., NPY, oxytocin, vasopressin, ghrelin, hypocretin/orexin; Pedersen and Prange, 1979; Södersten et al., 1983; Clark et al., 1984; Sakurai et al., 1998; Nakazato et al., 2001). We employ a similar strategy by inducing neuropeptide expression at the genetic level. Second, although gain-of-function approaches cannot establish an essential or endogenous role for a neuropeptide, they result in signaling pathway activation that overcomes the problem of redundancy found in lossof-function assays. Third, the conditional induction of peptide expression only during the behavioral assays avoids the earlier developmental, physiological, or compensatory effects that often limit loss-of-function approaches. For example, block of nociceptin signaling during embryogenesis leads to defects in placode progenitor formation (Lleras-Forero et al., 2013). Although the conditional induction approach cannot uncover functions caused by distinct patterns of activity (e.g., tonic vs phasic release of a neuropeptide), it avoids the indirect effects caused by long-term loss or gain of neuropeptide expression. Based on this rationale, we studied the effects of conditional neuropeptide misexpression on arousal behaviors in zebrafish larvae (Figs. 5-9; Tables 2-5). In total, we obtained 119 different behavioral measurements over $\begin{array}{cc}\text { Waking Activity } & \text { Rest } \\ \text { (sec / waking min) } & (\min / 10 \mathrm{~min})\end{array}$
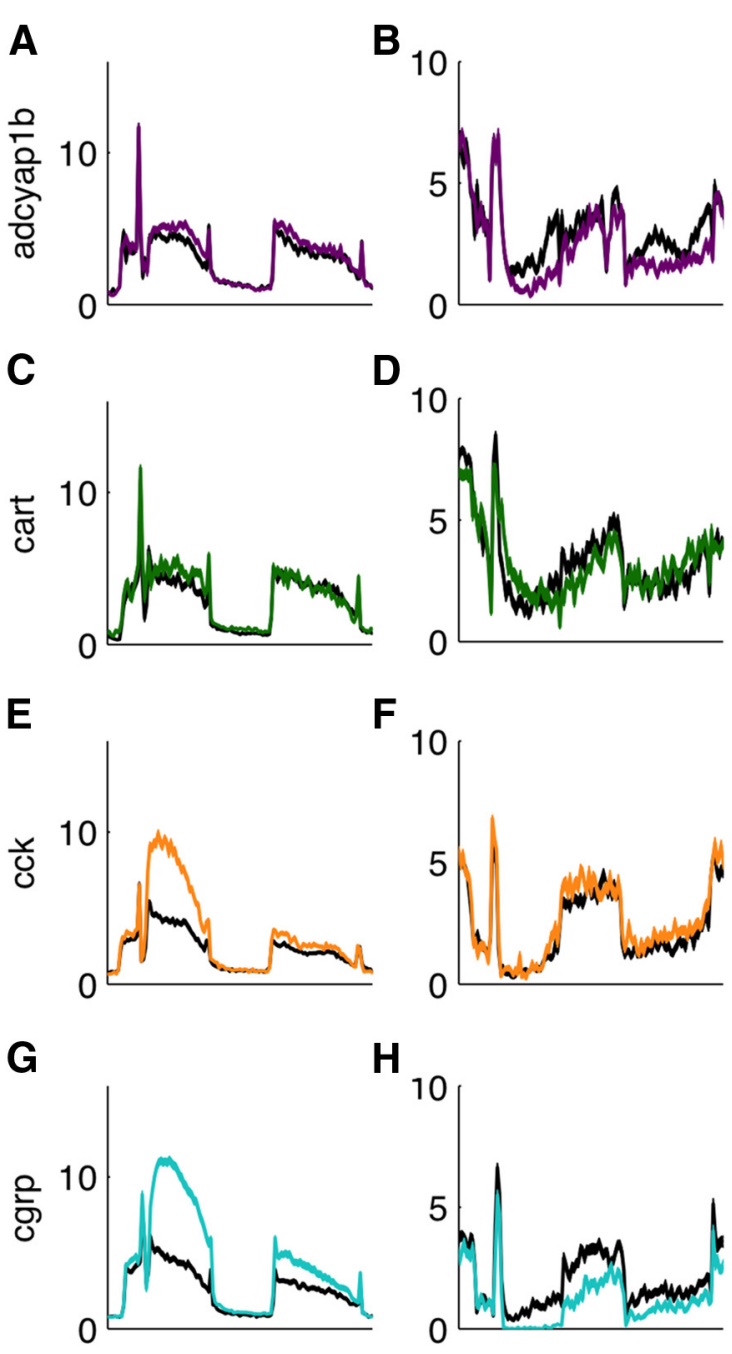

H
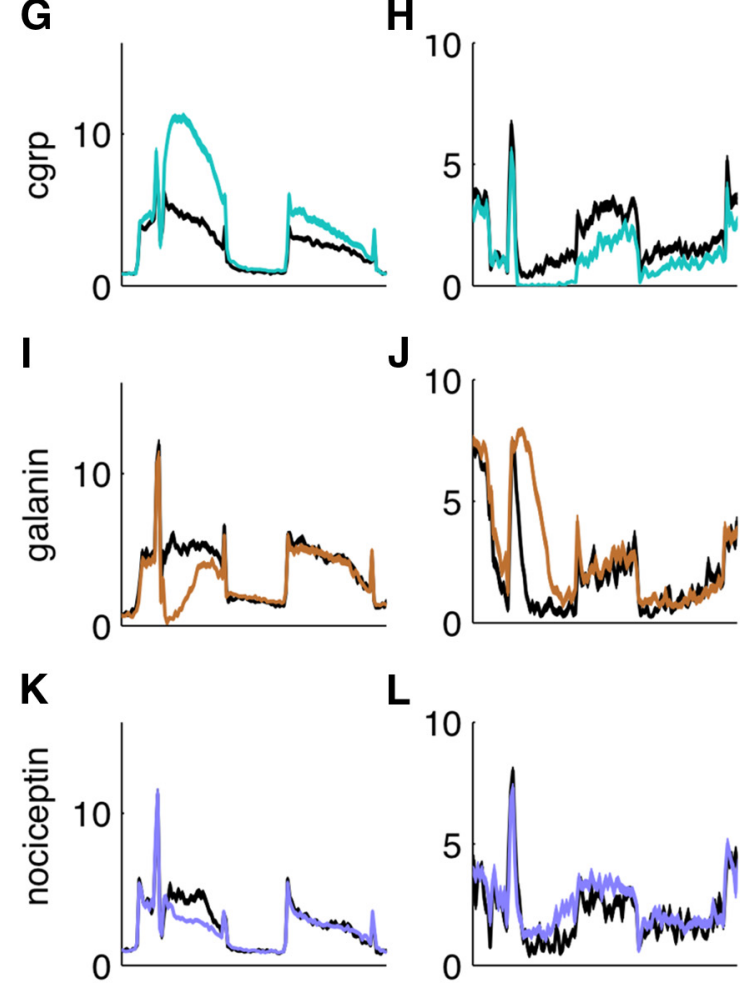

\begin{tabular}{|c|c|}
\hline $\begin{array}{c}\text { Waking } \\
\text { Activity }\end{array}$ & Rest \\
\hline $\begin{array}{c}\text { Movement } \\
\text { Amplitude }\end{array}$ & $\begin{array}{c}\text { Movement } \\
\text { Duration }\end{array}$ \\
\hline $\begin{array}{c}\text { Movement } \\
\text { Frequency }\end{array}$ & $\begin{array}{c}\text { Bout } \\
\text { Duration }\end{array}$ \\
\hline Bout & Rest \\
Frequency & Latency \\
\hline
\end{tabular}

\begin{tabular}{|c|c|}
\hline $\begin{array}{c}\text { Waking } \\
\text { Activity }\end{array}$ & Rest \\
\hline $\begin{array}{c}\text { Movement } \\
\text { Amplitude }\end{array}$ & $\begin{array}{c}\text { Movement } \\
\text { Duration }\end{array}$ \\
\hline Movement & Bout \\
Frequency & Duration \\
\hline Bout & Rest \\
Frequency & Latency \\
\hline
\end{tabular}

\begin{tabular}{|c|c|}
\hline $\begin{array}{c}\text { Waking } \\
\text { Activity }\end{array}$ & Rest \\
\hline $\begin{array}{c}\text { Movement } \\
\text { Amplitude }\end{array}$ & $\begin{array}{c}\text { Movement } \\
\text { Duration }\end{array}$ \\
\hline Movement & Bout \\
Frequency & Duration \\
\hline Bout & Rest \\
Frequency & Latency \\
\hline
\end{tabular}

Figure 5. Neuropeptidergic modulation of locomotor activity. Activity and rest plots were generated as in Figure 1 for larvae overexpressing adcyap $1 b(\boldsymbol{A}, \boldsymbol{B}$, purple), cart (C, D, green), cck $(\boldsymbol{E}, \boldsymbol{F}$, yellow), cgrp $(\boldsymbol{G}, \boldsymbol{H}$, aqua $)$, galanin $(\boldsymbol{I}, \boldsymbol{J}$, brown), nociceptin $(\boldsymbol{K}, \boldsymbol{L}$, blue), and their respective wild-type siblings (black). Shading represents mean \pm SEM. Summaries of comparisons between peptide-overexpressing fish and their wild-type siblings are shown to the right of the figure. Statistically significant increases in locomotor behaviors for day 5 depicted in yellow, while statistically significant decreases are shown in blue. See Table 2 for $p$ values. Significance thresholds at the 0.05 level were corrected for multiple comparisons with the Holm-Bonferroni method. 


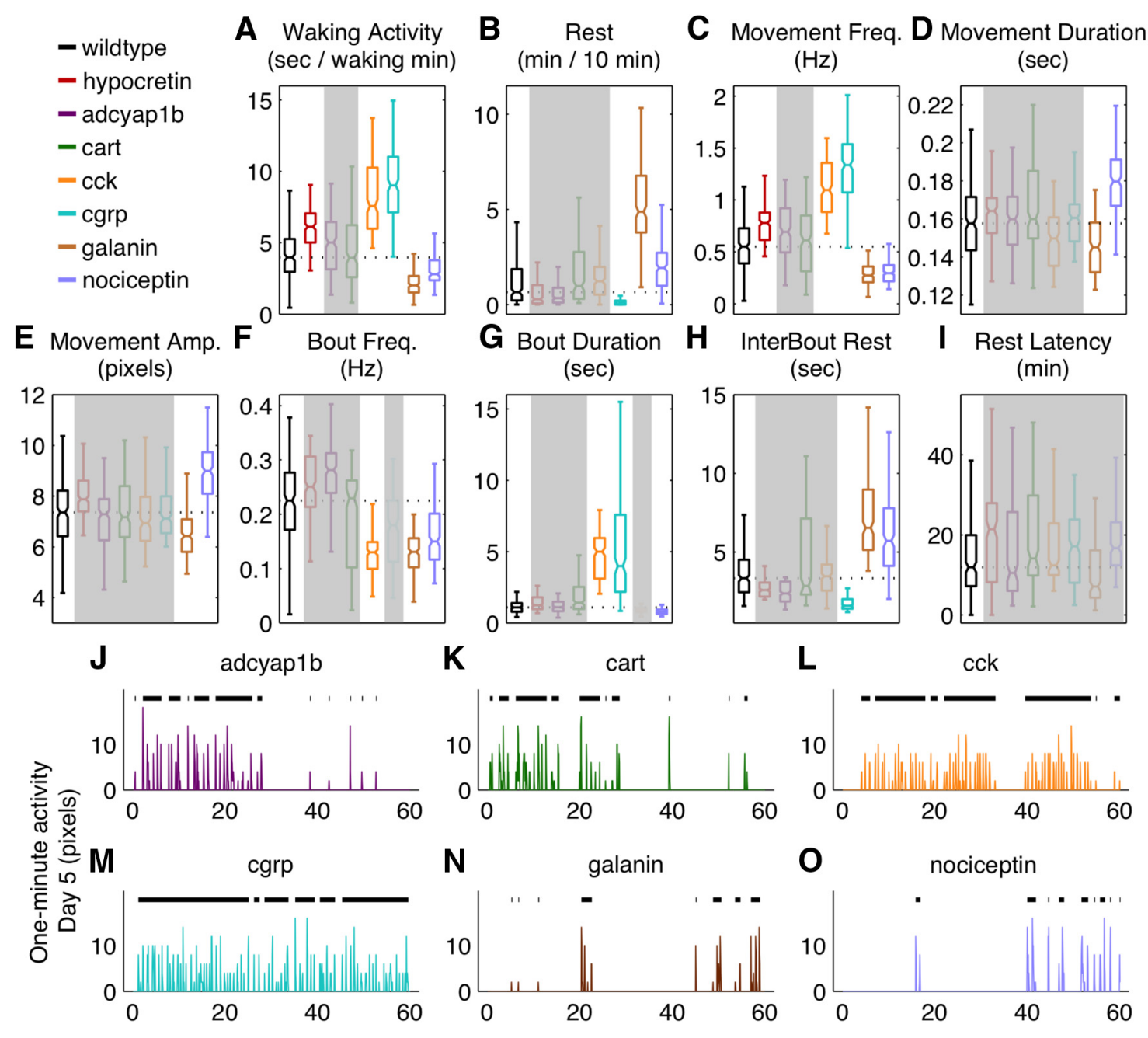

Figure 6. Comparison of peptide-induced locomotor phenotypes on $5 \mathrm{dpf}$ at $15 \mathrm{~Hz}$ resolution. Each panel shows box-and-whisker plots as in Figure 2. The median wild-type value for each parameter is shown by the horizontal dashed line. Statistical comparisons were performed by Kruskal-Wallis ANOVA and Tukey's honestly significant difference criteria for multiple comparisons; bold color delineates difference from the wild-type distributions at $99.9 \%$ confidence level $(p<0.001)$. $\boldsymbol{A}$, Waking activity, as measured by the total time spent moving in 10 min intervals. $\boldsymbol{B}$, Rest bouts, defined as the number of 1 min spans of continuous inactivity in 10 min intervals. $\boldsymbol{C}$, Movement frequency, where a movement is defined as a pixel displacement preceded and followed by a rest interval at the temporal limit of resolution (i.e., $67 \mathrm{~ms}$ ). D, Movement duration, defined as the average length of pixel displacement per movement, as defined in $\boldsymbol{C}$. $\boldsymbol{E}$, Movement amplitude, defined by the mean maximum amplitude per movement, as defined in $\boldsymbol{C}$. $\boldsymbol{F}$, Bout frequency, where a bout is defined as a cluster of movements separated by $\leq 1 \mathrm{~s}$ of inactivity. $\mathbf{G}$, Bout duration, as defined in $\boldsymbol{F}$. $\boldsymbol{H}$, Interbout rest, or the average amount of time elapsed between movement bouts, as defined in $\boldsymbol{F}$. $\boldsymbol{I}$, Rest latency, defined by the average number of minutes elapsed between lights out on $5 \mathrm{dpf}$ and the first $1 \mathrm{~min}$ period of inactivity. $\mathbf{J}-\mathbf{0}$, Statistically typical movement profiles on $5 \mathrm{dpf}$ for the indicated genotypes, based on the 1 min window of data that most closely matches measured values for movement frequency, movement amplitude, movement duration, bout frequency, and bout duration. Movement bouts are delineated by horizontal black lines above each activity trace.

the course of our experiments ( 7 peptides $\times 17$ measurements). Results of all measurements and peptides are summarized as a heatmap in Figure $9 A$.

\section{Neuropeptidergic regulation of spontaneous \\ locomotor activity}

To test whether neuropeptides influenced spontaneous locomotor activity, we placed transgenic larvae and their wild-type siblings into a videotracking device in the afternoon of $4 \mathrm{dpf}(\sim 100$ hpf), and induced neuropeptide expression via heatshock at noon on $5 \mathrm{dpf}$. Locomotor behavior was analyzed through $6 \mathrm{dpf}$. Peptide expression induced a wide range of phenotypes (Fig. 5; Table 2). For example, cck and cgrp induced increases in waking activity on $\mathrm{d} 5$, similar to hypocretin (Fig. $5 E, G$; Table 2), whereas opposite effects were induced by galanin and nociceptin (Fig. 5I, K; Table 2). In addition, cgrp was similar to hypocretin in that this peptide induced a reduction in rest (Fig. $5 H$; Table 2), whereas galanin and nociceptin increased rest (Fig. 5J,L; Table 2).

To determine whether activity and rest are interdependent aspects of locomotor behavior, we compared the rest/wake profiles induced by neuropeptides. Although some neuropeptides (e.g., cgrp and galanin) induced phenotypes in which rest and activity were altered in opposite directions, rest/wake behaviors were not always inversely correlated. For example, cck had no effect on rest bouts (Figs. 5F, 6B; Table 2), in contrast to its strong enhancement of waking activity (Figs. $5 E, 6 A$ ). In addition, the movement architecture induced by cck was distinct: cck induced longer movement bouts (Fig. 6G) at a lower frequency (Fig. $6 F$ ) than other activating peptides (hypocretin and cgrp), yet rest intervals between bouts were equivalent to those of wild-type siblings (Fig. $6 \mathrm{H}$; Table 2). Thus, the comparison of locomotor behaviors across the panel of neuropep- 


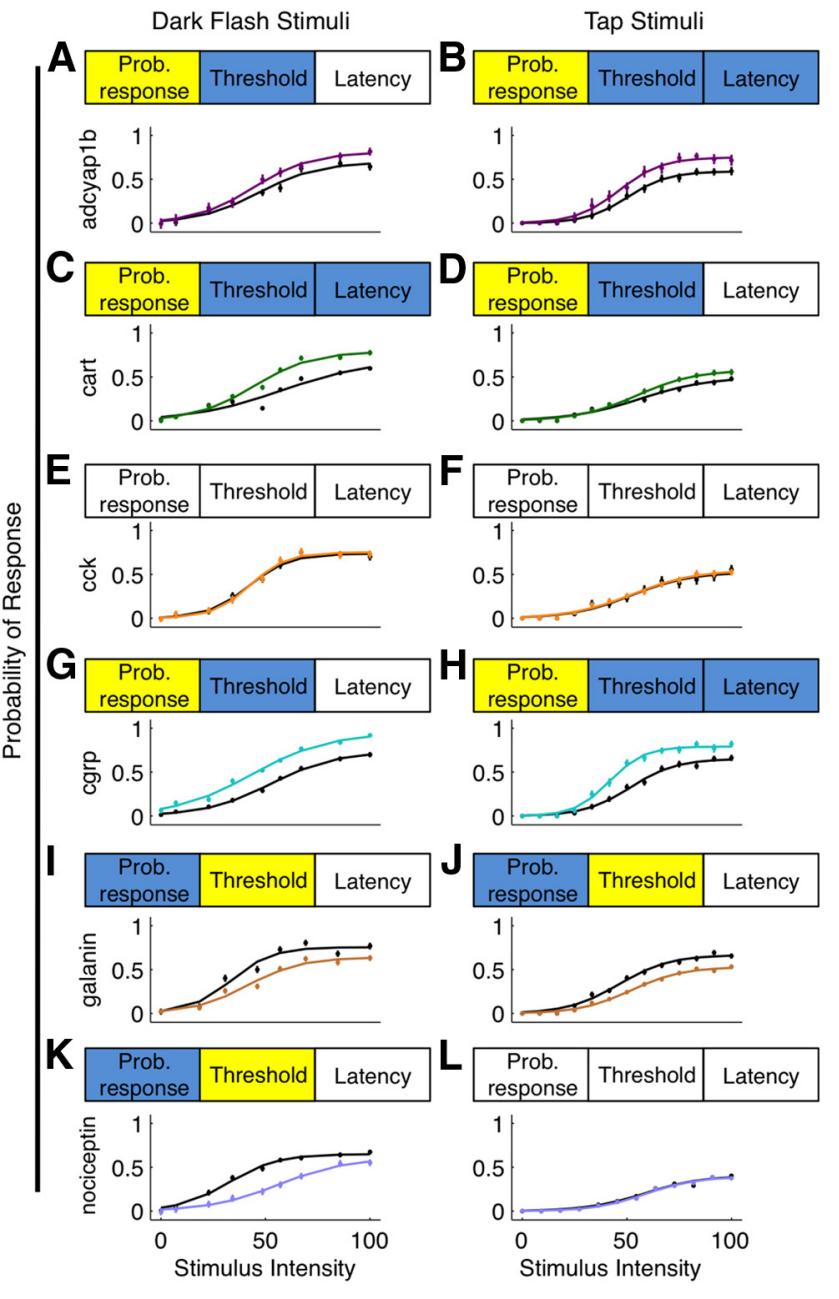

Figure 7. Neuropeptidergic modulation of response to dark-flash and tap stimuli. Stimulus delivery, data acquisition, and response analysis are as in Figure 3. Responses were recorded during circadian night following $5 \mathrm{dpf}$. Response probability \pm SEM is indicated for each stimulus intensity, overlaid with best-fit sigmoid curves. Statistically significant increases are depicted in yellow, while statistically significant decreases are shown in blue. See Table 4 for $p$ values. Significance thresholds at the 0.05 level were corrected for multiple comparisons with the Holm-Bonferroni method. $\boldsymbol{A}-\boldsymbol{H}$, Adcyap $1 \mathrm{~b}$, cart, and cgrp increased probability of response and decreased stimulus threshold for both dark-flash and tap stimuli. In addition, adcyap $1 \mathrm{~b}$ and cgrp decreased latency for response to the tap stimuli $(\boldsymbol{B}, \boldsymbol{H})$, while cart decreased latency for response to the dark-flash stimuli (C). $\boldsymbol{E}-\boldsymbol{F}$, Responsiveness of cck-expressing larvae was indistinguishable from their wild-type siblings. $I-J$, Galanin decreased probability of response and increased the response threshold for both stimulus modalities. $\boldsymbol{K}$, Nociceptin expression decreased response probability to the dark-flash stimuli, and increased the stimulus threshold. $L$, Responsiveness of nociceptin-expressing larvae to tap stimuli was indistinguishable from that of their wild-type siblings.

tides indicates that individual components of active and rest states are clearly separable.

To test whether independent behaviors could underlie emergent patterns of locomotor activity, we compared individual parameters of behavior associated with active locomotion. For example, both galanin and nociceptin decreased waking activity during the day (Figs. $5 I, K, 6 A$ ), yet nociceptin increased movement amplitude (Fig. $6 E$ ) and duration (Fig. $6 D$ ), whereas the opposite effects were observed upon galanin expression (Table 2 ). To directly visualize and compare these parameters across peptides, we identified periods of locomotion that best exemplified the locomotor attributes quantified for each peptide (Fig. $6 J-O)$. Together, this high-resolution analysis revealed that neu-

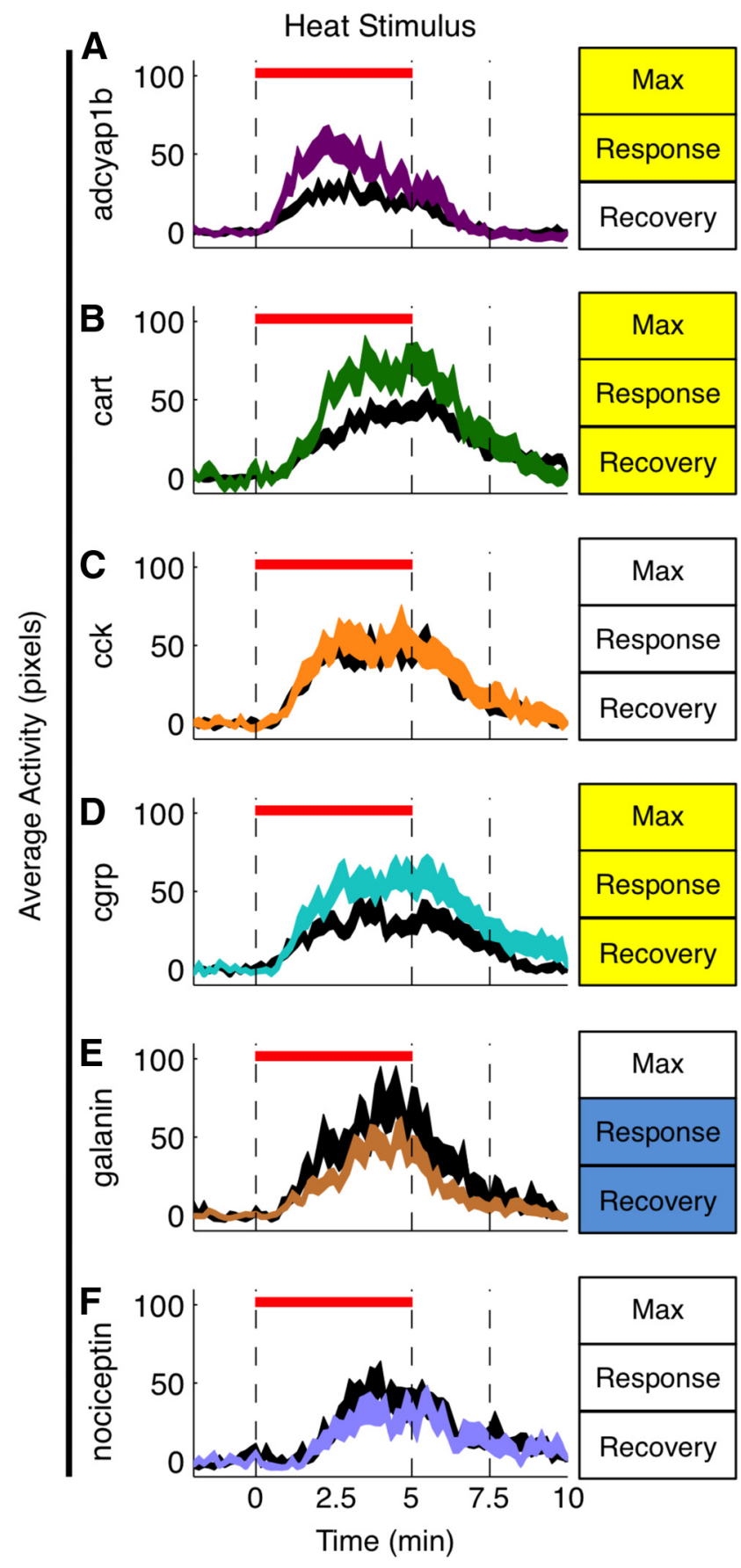

Figure 8. Neuropeptidergic modulation of response to thermal stimuli. Stimulus delivery, data acquisition, and response analysis are as in Figure 3. Responses were recorded during circadian morning on $6 \mathrm{dpf}$. The width of the plots represents \pm SEM. Statistically significant increases are depicted in yellow, while statistically significant decreases are shown in blue. See Table 4 for $p$ values. Significance thresholds at the 0.05 level were corrected for multiple comparisons with the Holm-Bonferroni method. $\boldsymbol{A}, \boldsymbol{B}-\boldsymbol{E}$, Cart ( $\boldsymbol{B})$ and $\operatorname{cgrp}(\boldsymbol{D})$ expression induced increases in all measured parameters, whereas adcyap $1 b(\boldsymbol{A})$ increased maximum activity and total response, and galanin $(\boldsymbol{E})$ decreased both total response and total recovery. $\boldsymbol{C}, \boldsymbol{F}$, Responsiveness of cck-expressing $(\boldsymbol{C})$ and nociceptin-expressing $(\boldsymbol{F})$ larvae to the heat stimulus was indistinguishable from that of their wild-type siblings.

ropeptides induce wide-ranging and diverse effects on spontaneous locomotor activity.

\section{Partitioning of arousal behaviors}

To determine whether spontaneous locomotor activity and sensory responsiveness are behaviorally separable or correlated, we 
A
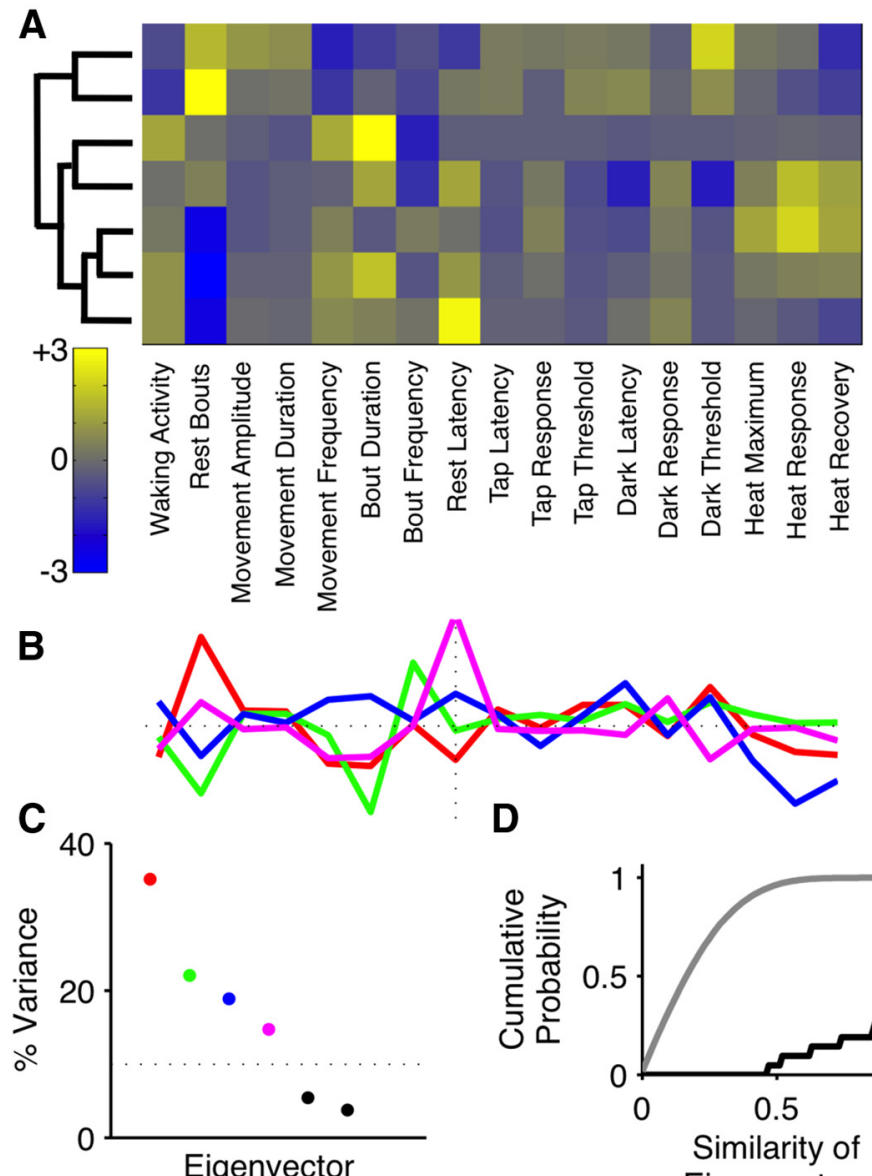

E

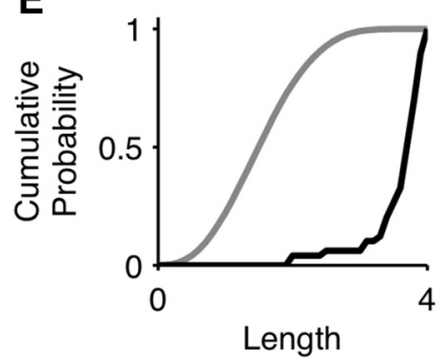

nociceptin

galanin

cck

cart

adcyap1b

cgrp

hypocretin

(n)


Table 4. Analysis of sensory responsiveness in peptide-overexpressing larvae

\begin{tabular}{|c|c|c|c|}
\hline & Wild-type siblings & HS-peptide & $p$ values \\
\hline \multicolumn{4}{|l|}{ Hypocretin } \\
\hline Light & $n=22$ & $n=42$ & \\
\hline Responsiveness ${ }^{a}$ & $0.63 \pm 0.03$ & $0.83 \pm 0.01$ & $6.60 \mathrm{E}-11$ \\
\hline Threshold & $34.94 \pm 0.38$ & $32.96 \pm 0.27$ & $1.70 \mathrm{E}-04$ \\
\hline Latency & $0.51 \pm 0.03$ & $0.57 \pm 0.03$ & 2.24E-01 \\
\hline Tap & $n=51$ & $n=43$ & \\
\hline Responsiveness $^{a}$ & $0.57 \pm 0.02$ & $0.54 \pm 0.03$ & 2.45E-01 \\
\hline Threshold & $48.26 \pm 0.34$ & $48.38 \pm 0.33$ & $6.24 \mathrm{E}-01$ \\
\hline Latency & $0.51 \pm 0.01$ & $0.51 \pm 0.01$ & $9.00 \mathrm{E}-01$ \\
\hline Heat & $n=44$ & $n=52$ & \\
\hline Maximum & $167.44 \pm 11.592$ & $172.3 \pm 8.677$ & 7.34E-01 \\
\hline Response & $830.34 \pm 82.721$ & $786.21 \pm 73.091$ & $6.89 \mathrm{E}-01$ \\
\hline Recovery & $496.38 \pm 67.384$ & $413.92 \pm 53.67$ & 3.35E-01 \\
\hline \multicolumn{4}{|l|}{ Adcyap1b } \\
\hline Light & $n=25$ & $n=22$ & \\
\hline Responsiveness $^{a}$ & $0.66 \pm 0.03$ & $0.79 \pm 0.03$ & $1.28 \mathrm{E}-03$ \\
\hline Threshold & $47.57 \pm 0.68$ & $44.90 \pm 0.80$ & $8.20 \mathrm{E}-03$ \\
\hline Latency & $0.47 \pm 0.02$ & $0.43 \pm 0.03$ & 2.24E- 01 \\
\hline Tap & $n=18$ & $n=10$ & \\
\hline Responsiveness ${ }^{a}$ & $0.59 \pm 0.03$ & $0.72 \pm 0.04$ & $1.52 \mathrm{E}-02$ \\
\hline Threshold & $50.78 \pm 0.48$ & $47.01 \pm 1.04$ & 3.45E-03 \\
\hline Latency & $0.71 \pm 0.01$ & $0.66 \pm 0.01$ & $1.83 \mathrm{E}-03$ \\
\hline Heat & $n=53$ & $n=42$ & \\
\hline Maximum & $88.73 \pm 6.561$ & $133.98 \pm 9.41$ & $1.03 \mathrm{E}-04$ \\
\hline Response & $561.88 \pm 68.569$ & $1090.6 \pm 139.52$ & $4.78 \mathrm{E}-04$ \\
\hline Recovery & $170.65 \pm 37.142$ & $257.82 \pm 71.18$ & 2.53E-01 \\
\hline \multicolumn{4}{|l|}{ Cart } \\
\hline Light & $n=50$ & $n=46$ & \\
\hline Responsiveness $^{a}$ & $0.57 \pm 0.02$ & $0.75 \pm 0.02$ & 2.54E-11 \\
\hline Threshold & $59.72 \pm 1.11$ & $44.60 \pm 0.33$ & $<1.00 \mathrm{E}-16$ \\
\hline Latency & $0.43 \pm 0.01$ & $0.32 \pm 0.01$ & $2.39 \mathrm{E}-08$ \\
\hline Tap & $n=55$ & $n=41$ & \\
\hline Responsiveness ${ }^{a}$ & $0.46 \pm 0.02$ & $0.55 \pm 0.03$ & $3.36 \mathrm{E}-03$ \\
\hline Threshold & $56.78 \pm 0.42$ & $54.97 \pm 0.35$ & 4.01E-03 \\
\hline Latency & $0.44 \pm 0.00$ & $0.44 \pm 0.00$ & $6.59 \mathrm{E}-01$ \\
\hline Heat & $n=60$ & $n=35$ & \\
\hline Maximum & $116.07 \pm 6.51$ & $148.18 \pm 9.27$ & $4.68 \mathrm{E}-03$ \\
\hline Response & $720.05 \pm 78.55$ & $1245.60 \pm 133.96$ & 4.70E-04 \\
\hline Recovery & $574.98 \pm 71.78$ & $866.54 \pm 110.56$ & $2.32 \mathrm{E}-02$ \\
\hline \multicolumn{4}{|l|}{ Cck } \\
\hline Light & $n=33$ & $n=31$ & \\
\hline Responsiveness $^{a}$ & $0.71 \pm 0.03$ & $0.73 \pm 0.03$ & 2.66E-01 \\
\hline Threshold & $42.28 \pm 0.25$ & $42.66 \pm 0.32$ & 4.01E-01 \\
\hline Latency & $0.52 \pm 0.02$ & $0.51 \pm 0.03$ & 4.89E-01 \\
\hline Тар & $n=27$ & $n=42$ & \\
\hline Responsiveness ${ }^{a}$ & $0.52 \pm 0.04$ & $0.52 \pm 0.03$ & $9.97 \mathrm{E}-01$ \\
\hline Threshold & $53.10 \pm 1.05$ & $53.25 \pm 0.51$ & $3.38 \mathrm{E}-01$ \\
\hline Latency & $0.42 \pm 0.01$ & $0.42 \pm 0.01$ & $8.92 \mathrm{E}-01$ \\
\hline Heat & $n=47$ & $n=25$ & \\
\hline Maximum & $118.25 \pm 6.36$ & $123.30 \pm 11.21$ & $6.73 \mathrm{E}-01$ \\
\hline Response & $959.39 \pm 85.11$ & $1067.20 \pm 146.29$ & 4.97E-01 \\
\hline Recovery & $548.92 \pm 71.69$ & $579.46 \pm 100.05$ & $8.04 \mathrm{E}-01$ \\
\hline \multicolumn{4}{|l|}{ Cgrp } \\
\hline Light & $n=56$ & $n=40$ & \\
\hline Responsiveness ${ }^{a}$ & $0.67 \pm 0.02$ & $0.88 \pm 0.01$ & $3.65 \mathrm{E}-13$ \\
\hline Threshold & $52.87 \pm 0.28$ & $44.34 \pm 0.74$ & $1.13 \mathrm{E}-13$ \\
\hline Latency & $0.51 \pm 0.01$ & $0.48 \pm 0.02$ & 2.32E-01 \\
\hline Tap & $n=27$ & $n=21$ & \\
\hline Responsiveness ${ }^{a}$ & $0.66 \pm 0.02$ & $0.80 \pm 0.03$ & $1.34 \mathrm{E}-04$ \\
\hline Threshold & $51.89 \pm 0.41$ & $42.00 \pm 0.37$ & $3.82 \mathrm{E}-09$ \\
\hline Latency & $0.44 \pm 0.01$ & $0.41 \pm 0.00$ & 2.25E-04 \\
\hline Heat & $n=44$ & $n=49$ & \\
\hline Maximum & $103.83 \pm 8.11$ & $145.41 \pm 11.14$ & $3.92 \mathrm{E}-03$ \\
\hline Response & $679.98 \pm 97.20$ & $1123.80 \pm 135.20$ & $1.05 \mathrm{E}-02$ \\
\hline \multirow[t]{2}{*}{ Recovery } & $436.93 \pm 89.09$ & \multirow{2}{*}{\multicolumn{2}{|c|}{$\begin{array}{r}2.39 \mathrm{E}-02 \\
\text { (Table Continues.) }\end{array}$}} \\
\hline & & & \\
\hline
\end{tabular}

Table 4. Continued

\begin{tabular}{|c|c|c|c|}
\hline & Wild-type siblings & HS-peptide & $p$ values \\
\hline \multicolumn{4}{|l|}{ Galanin } \\
\hline Light & $n=30$ & $n=65$ & \\
\hline Responsiveness $^{a}$ & $0.72 \pm 0.0249$ & $0.60 \pm 0.02$ & $1.02 \mathrm{E}-02$ \\
\hline Threshold & $34.2 \pm 0.4468$ & $41.305 \pm 0.26$ & $2.34 \mathrm{E}-14$ \\
\hline Latency & $0.58 \pm 0.0481$ & $0.67 \pm 0.05$ & $3.53 \mathrm{E}-01$ \\
\hline Tар & $n=41$ & $n=51$ & \\
\hline Responsiveness $^{a}$ & $0.67 \pm 0.02$ & $0.51 \pm 0.02$ & $5.87 \mathrm{E}-08$ \\
\hline Threshold & $46.40 \pm 0.36$ & $52.38 \pm 0.25$ & $9.21 \mathrm{E}-15$ \\
\hline Latency & $0.43 \pm 0.00$ & $0.44 \pm 0.00$ & $6.63 \mathrm{E}-01$ \\
\hline Heat & $n=30$ & $n=65$ & \\
\hline Maximum & $188.19 \pm 15.13$ & $154.87 \pm 9.57$ & $5.90 \mathrm{E}-02$ \\
\hline Response & $1119.70 \pm 137.06$ & $728.35 \pm 81.43$ & $1.15 \mathrm{E}-02$ \\
\hline Recovery & $615.22 \pm 116.48$ & $333.42 \pm 64.15$ & $2.43 \mathrm{E}-02$ \\
\hline \multicolumn{4}{|l|}{ Nociceptin } \\
\hline Light & $n=58$ & $n=37$ & \\
\hline Responsiveness $^{a}$ & $0.66 \pm 0.02$ & $0.55 \pm 0.03$ & $1.61 \mathrm{E}-03$ \\
\hline Threshold & $33.04 \pm 0.45$ & $56.85 \pm 0.64$ & $2.22 \mathrm{E}-16$ \\
\hline Latency & $0.50 \pm 0.02$ & $0.48 \pm 0.02$ & $4.19 \mathrm{E}-01$ \\
\hline Tap & $n=42$ & $n=49$ & \\
\hline Responsiveness $^{a}$ & $0.39 \pm 0.02$ & $0.38 \pm 0.02$ & $5.53 \mathrm{E}-01$ \\
\hline Threshold & $59.13 \pm 0.52$ & $59.07 \pm 0.42$ & $9.43 \mathrm{E}-01$ \\
\hline Latency & $0.47 \pm 0.01$ & $0.47 \pm 0.01$ & $9.62 \mathrm{E}-01$ \\
\hline Heat & $n=40$ & $n=44$ & \\
\hline Maximum & $137.73 \pm 12.812$ & $134.19 \pm 9.8304$ & $8.25 \mathrm{E}-01$ \\
\hline Response & $680.57 \pm 115.21$ & $627.59 \pm 85.381$ & $7.09 \mathrm{E}-01$ \\
\hline Recovery & $418.79 \pm 80.359$ & $251.65 \pm 65.666$ & $1.09 \mathrm{E}-01$ \\
\hline
\end{tabular}

Values are mean \pm SEM $p$ values from Kruskall-Wallis one-way ANOVA.

${ }^{a}$ Maximum probability of response at the strongest stimuli.

induced phenotypes were summarized in a $7 \times 17$ grid (Fig. $9 A$ ), where each row represents a single peptide and each column represents the effect of each peptide on different behavioral parameters, normalized across all experiments. We then built a model of phenotypes by performing a principal components analysis $(\mathrm{PCA})$ on the $7 \times 17$ grid. Figure $9 \mathrm{C}$ shows a scree plot of the variance explained by each eigenvector identified in the PCA; the first four (in color) explain $>90 \%$ of the variance. These eigenvectors (Fig. 9B) thus quantitatively define aspects of arousal-associated behavioral phenotypes that covary across our dataset. In the first (red) eigenvector, behaviors associated with increased activity were mostly inversely correlated with behaviors associated with rest. For example, the strong peak at rest bout length was opposite in sign to the peaks associated with movement frequency and latency to rest. In contrast, the other eigenvectors suggest that parameters associated with increased activity could be positively correlated with parameters associated with increased rest. For example, in the second (green) eigenvector, rest bout duration was positively correlated with active bout duration. Similarly, in the third (blue) eigenvector, movement frequency was inversely correlated with responsiveness to sensory stimuli. Thus, activating phenotypes in one assay were sometimes associated with inactivating phenotypes in another, and vice versa. This unbiased quantitative analysis reinforced the conclusion that arousal-related phenotypes could be partitioned into individual behavioral components.

To assess the range of arousal-associated changes in our analyses, we determined how much new information was provided when a novel neuropeptide was added. We ran a series of analyses in which we left out each peptide sequentially, performed a PCA on the remaining peptides, and thereby generated a set of new models, one for each "left-out" peptide. These new models were subjected to three tests to assess how fully our original model 
Table 5. Analysis of sensory responsiveness in transgenic larvae without heatshock

\begin{tabular}{|c|c|c|c|}
\hline & Wild-type siblings & HS-peptide & $\overline{p \text { values }}$ \\
\hline \multicolumn{4}{|l|}{ Hypocretin } \\
\hline Light & $n=39$ & $n=35$ & \\
\hline Responsiveness ${ }^{a}$ & $0.70 \pm 0.02$ & $0.77 \pm 0.02$ & $5.20 \mathrm{E}-02$ \\
\hline Threshold & $42.15 \pm 0.27$ & $44.31 \pm 0.38$ & $3.80 \mathrm{E}-02$ \\
\hline Latency & $0.89 \pm 0.04$ & $0.86 \pm 0.3$ & $8.24 \mathrm{E}-01$ \\
\hline Тар & $n=52$ & $n=41$ & \\
\hline Responsiveness $^{a}$ & $0.37 \pm 0.01$ & $0.35 \pm 0.01$ & $3.74 \mathrm{E}-01$ \\
\hline Threshold & $42.92 \pm 0.38$ & $42.88 \pm 0.32$ & $8.16 \mathrm{E}-01$ \\
\hline Latency & $0.74 \pm 0.01$ & $0.69 \pm 0.01$ & $8.77 \mathrm{E}-02$ \\
\hline Heat & $n=11$ & $n=19$ & \\
\hline Maximum & $133.01 \pm 9.87$ & $134.02 \pm 7.29$ & $9.35 \mathrm{E}-01$ \\
\hline Response & $948 \pm 133.31$ & $661.41 \pm 131.13$ & $1.64 \mathrm{E}-01$ \\
\hline Recovery & $591.6 \pm 101.52$ & $595.53 \pm 88.51$ & $9.78 \mathrm{E}-01$ \\
\hline \multicolumn{4}{|l|}{ Adcyap1b } \\
\hline Light & $n=57$ & $n=38$ & \\
\hline Responsiveness ${ }^{a}$ & $0.74 \pm 0.02$ & $0.78 \pm 0.02$ & $7.42 \mathrm{E}-01$ \\
\hline Threshold & $43.14 \pm 0.17$ & $42.50 \pm 0.22$ & $2.45 \mathrm{E}-02$ \\
\hline Latency & $0.76 \pm 0.03$ & $0.79 \pm 0.03$ & $3.91 \mathrm{E}-01$ \\
\hline Tар & $n=45$ & $n=48$ & \\
\hline Responsiveness ${ }^{a}$ & $0.52 \pm 0.02$ & $0.51 \pm 0.02$ & $7.23 \mathrm{E}-01$ \\
\hline Threshold & $35.93 \pm 0.06$ & $35.98 \pm 0.13$ & $6.01 \mathrm{E}-01$ \\
\hline Latency & $0.54 \pm 0.01$ & $0.53 \pm 0.01$ & $6.28 \mathrm{E}-01$ \\
\hline Heat & $n=57$ & $n=38$ & \\
\hline Maximum & $76.67 \pm 4.37$ & $89.87 \pm 6.14$ & $7.49 \mathrm{E}-02$ \\
\hline Response & $364.27 \pm 85.43$ & $481.58 \pm 113.49$ & 4.03E-01 \\
\hline Recovery & $173.23 \pm 65.34$ & $161.11 \pm 88.68$ & $9.11 \mathrm{E}-01$ \\
\hline \multicolumn{4}{|l|}{ Cart } \\
\hline Light & $n=41$ & $n=39$ & \\
\hline Responsiveness ${ }^{a}$ & $0.55 \pm 0.02$ & $0.60 \pm 0.02$ & $2.18 \mathrm{E}-01$ \\
\hline Threshold & $44.97 \pm 0.64$ & $43.19 \pm 0.61$ & 6.67E-02 \\
\hline Latency & $0.55 \pm 0.02$ & $0.55 \pm 0.02$ & 7.60E-01 \\
\hline Tap & $n=42$ & $n=48$ & \\
\hline Responsiveness ${ }^{a}$ & $0.59 \pm 0.02$ & $0.56 \pm 0.02$ & 3.37E-01 \\
\hline Threshold & $31.41 \pm 0.44$ & $31.51 \pm 0.27$ & $3.40 \mathrm{E}-01$ \\
\hline Latency & $0.85 \pm 0.01$ & $0.85 \pm 0.01$ & $5.50 \mathrm{E}-01$ \\
\hline Heat & $n=57$ & $n=36$ & \\
\hline Maximum & $179.71 \pm 9.07$ & $196.67 \pm 12.09$ & $2.59 \mathrm{E}-01$ \\
\hline Response & $1514.8 \pm 102.32$ & $1790.9 \pm 173.8$ & 1.47E-01 \\
\hline Recovery & $741.51 \pm 90.51$ & $786.37 \pm 140.48$ & $7.79 \mathrm{E}-01$ \\
\hline \multicolumn{4}{|l|}{ Cck } \\
\hline Light & $n=20$ & $n=39$ & \\
\hline Responsiveness $^{a}$ & $0.44 \pm 0.04$ & $0.44 \pm 0.02$ & $9.41 \mathrm{E}-01$ \\
\hline Threshold & $49.99 \pm 0.64$ & $46.13 \pm 0.31$ & $2.32 \mathrm{E}-02$ \\
\hline Latency & $0.91 \pm 0.06$ & $0.83 \pm 0.03$ & $3.70 \mathrm{E}-01$ \\
\hline Tар & $n=27$ & $n=25$ & \\
\hline Responsiveness ${ }^{a}$ & $0.68 \pm 0.03$ & $0.72 \pm 0.03$ & 3.13E-01 \\
\hline Threshold & $49.33 \pm 0.33$ & $48.28 \pm 0.46$ & 5.33E-02 \\
\hline Latency & $0.68 \pm 0.01$ & $0.69 \pm 0.01$ & $3.65 \mathrm{E}-01$ \\
\hline Heat & $n=44$ & $n=40$ & \\
\hline Maximum & $74.64 \pm 5.79$ & $79.68 \pm 6.63$ & 5.67E-01 \\
\hline Response & $395.19 \pm 52.23$ & $459.17 \pm 84.13$ & $5.12 \mathrm{E}-01$ \\
\hline Recovery & $200.01 \pm 45.93$ & $368.35 \pm 73.07$ & $5.02 \mathrm{E}-02$ \\
\hline \multicolumn{4}{|l|}{ Cgrp } \\
\hline Light & $n=40$ & $n=42$ & \\
\hline Responsiveness $^{a}$ & $0.57 \pm 0.03$ & $0.58 \pm 0.03$ & $5.01 \mathrm{E}-01$ \\
\hline Threshold & $43.25 \pm 0.27$ & $43.54 \pm 0.34$ & $6.76 \mathrm{E}-01$ \\
\hline Latency & $0.85 \pm 0.04$ & $0.91 \pm 0.04$ & $2.73 \mathrm{E}-01$ \\
\hline Tap & $n=39$ & $n=43$ & \\
\hline Responsiveness ${ }^{a}$ & $0.40 \pm 0.02$ & $0.40 \pm 0.02$ & 7.57E-01 \\
\hline Threshold & $57.32 \pm 0.23$ & $57.41 \pm 0.25$ & 7.81E-01 \\
\hline Latency & $0.47 \pm 0.01$ & $0.49 \pm 0.01$ & $3.68 \mathrm{E}-02$ \\
\hline Heat & $n=43$ & $n=40$ & \\
\hline Maximum & $101.86 \pm 6.16$ & $110.92 \pm 6.03$ & 2.97E-01 \\
\hline Response & $603.57 \pm 90.09$ & $585.36 \pm 69.53$ & $8.72 \mathrm{E}-01$ \\
\hline Recovery & $352.82 \pm 72.59$ & $344.08 \pm 63.52$ & $9.28 \mathrm{E}-01$ \\
\hline \multicolumn{4}{|c|}{ (Table Continues.) } \\
\hline
\end{tabular}

Table 5. Continued

\begin{tabular}{|c|c|c|c|}
\hline & Wild-type siblings & HS-peptide & $p$ values \\
\hline \multicolumn{4}{|l|}{ Galanin } \\
\hline Light & $n=46$ & $n=42$ & \\
\hline Responsiveness $^{a}$ & $0.46 \pm 0.03$ & $0.37 \pm 0.03$ & $2.11 \mathrm{E}-02$ \\
\hline Threshold & $45.44 \pm 0.20$ & $45.17 \pm 0.33$ & 4.46E-01 \\
\hline Latency & $0.55 \pm 0.03$ & $0.58 \pm 0.03$ & $4.66 \mathrm{E}-01$ \\
\hline Tар & $n=49$ & $n=47$ & \\
\hline Responsiveness $^{a}$ & $0.62 \pm 0.02$ & $0.61 \pm 0.02$ & $9.61 \mathrm{E}-01$ \\
\hline Threshold & $49.67 \pm 0.19$ & $50.44 \pm 0.22$ & $9.78 \mathrm{E}-03$ \\
\hline Latency & $0.87 \pm 0.01$ & $0.87 \pm 0.01$ & $7.61 \mathrm{E}-01$ \\
\hline Heat & $n=13$ & $n=35$ & \\
\hline Maximum & $131.4 \pm 12.32$ & $110.57 \pm 6.56$ & $1.19 \mathrm{E}-01$ \\
\hline Response & $776.91 \pm 117.76$ & $609.45 \pm 97.06$ & $3.44 \mathrm{E}-01$ \\
\hline Recovery & $513.44 \pm 97.57$ & $441.78 \pm 67.06$ & $5.70 \mathrm{E}-01$ \\
\hline \multicolumn{4}{|l|}{ Nociceptin } \\
\hline Light & $n=47$ & $n=48$ & \\
\hline Responsiveness $^{a}$ & $0.72 \pm 0.02$ & $0.74 \pm 0.02$ & $3.50 \mathrm{E}-01$ \\
\hline Threshold & $36.34 \pm 0.34$ & $35.69 \pm 0.36$ & $2.44 \mathrm{E}-01$ \\
\hline Latency & $0.72 \pm 0.06$ & $0.66 \pm 0.06$ & $3.71 \mathrm{E}-01$ \\
\hline Tap & $n=39$ & $n=40$ & \\
\hline Responsiveness $^{a}$ & $0.61 \pm 0.02$ & $0.61 \pm 0.02$ & $9.87 \mathrm{E}-01$ \\
\hline Threshold & $48.73 \pm 0.23$ & $49.15 \pm 0.37$ & 5.57E-01 \\
\hline Latency & $0.40 \pm 0.01$ & $0.40 \pm 0.00$ & $5.35 \mathrm{E}-01$ \\
\hline Heat & $n=44$ & $n=44$ & \\
\hline Maximum & $88.98 \pm 5.15$ & $95.08 \pm 6.40$ & $4.59 \mathrm{E}-01$ \\
\hline Response & $501.35 \pm 69.98$ & $513.86 \pm 59.99$ & $8.92 \mathrm{E}-01$ \\
\hline Recovery & $278.61 \pm 51.04$ & $338.67 \pm 56.13$ & $4.31 \mathrm{E}-01$ \\
\hline
\end{tabular}

Values are mean \pm SEM $p$ values from Kruskall-Wallis one-way ANOVA.

${ }^{a}$ Maximum probability of response at the strongest stimuli.

represents the potential range of induced behaviors. First, we took the absolute value of the dot product (a measure of vector similarity, normalized so that 0 indicated no similarity, and 1 indicated a perfect match) between the first four eigenvectors generated in our "left-out" analysis and those derived from the full model. We then compared values with similar values obtained via a "null" model, in which eigenvectors were similarly generated from randomly shuffled data (Fig. 9D). Second, we compared how far each peptide was from the origin in the fourdimensional space defined by PCA upon the six remaining peptides to its locus in a space defined by shuffled data (Fig. 9E). Third, we compared the distance between peptides within our model and a model derived from randomized data (Fig. $9 F$ ). All three tests indicated that our dataset encompasses a wide range of possible phenotypes following neuropeptide expression, suggesting that our characterization is general and robust.

\section{Conserved and novel functions of neuropeptides in arousal}

Our systematic and parallel analysis allowed us to directly compare the functions of different neuropeptides and their relationships with previously suggested roles in mammalian sleep/wake behaviors, sensory responsiveness, and anxiety.

\section{Spontaneous locomotor activity \\ Hypocretin}

Numerous studies in mammals support a wake-promoting role for hypocretin (de Lecea et al., 2012). These functions are conserved in zebrafish, as described at low-temporal resolution by Prober et al. (2006) and shown at higher resolution in Figure 2.

Cgrp

There are conflicting interpretations of the role of cgrp in mammals. For example, injection of cgrp into the mammalian brain was found to decrease locomotion, whereas inhibition of cgrp 
function increases locomotion (Kovács et al., 1999; SchorscherPetcu et al., 2009). However, other experiments suggest that cgrp increases rearing and grooming movements, and increases anxiety-like behaviors, such as acoustic startle magnitude and time spent in the open arms of an elevated plus maze (Kovács et al., 1999; Sink et al., 2011). Our assays suggest that cgrp may function similarly to hypocretin to increase spontaneous locomotion. Like hypocretin (Prober et al., 2006), expression of cgrp increased locomotor activity and decreased rest (Fig. 6). In addition, cgrp, like hypocretin, induced an insomnia-like phenotype in zebrafish larvae, characterized in part by an increased latency to rest upon night onset (Fig. 6; Table 2; Prober et al., 2006). Our data also suggest that muscle contractions underlying individual movements are unchanged upon cgrp expression, as neither movement amplitude nor duration were increased. Rather, cgrp, similar to hypocretin, increased activity primarily by increasing frequency of movement initiation (Figs. $2 G, K, 6$ ).

\section{Cart}

Cart peptide has been proposed to promote wakefulness in mammals (Keating et al., 2010). In contrast, cart exerted minimal effects upon sleep/wake behaviors in zebrafish larvae, yet enhanced responsiveness to all sensory stimuli examined (Figs. $5 C, D ; 6,7 C, D, 8 B)$. Our data therefore suggest that cart may primarily activate sensory responsiveness in larval zebrafish, without affecting spontaneous locomotor activity.

\section{Galanin}

Galanin-positive neurons in the ventrolateral preoptic area are active during sleep, send inhibitory projections to structures within the ascending arousal system, and suppress arousalpromoting neurons within the locus ceruleus in vitro (Seutin et al., 1989; Pieribone et al., 1995; Sherin et al., 1998, Szymusiak et al., 1998). While these data suggest that galanin may be a sleeppromoting peptide, this function has not been conclusively demonstrated in vivo. Our assays uncover striking behavioral changes induced by galanin activity: both spontaneous locomotion and sensory responsiveness were inhibited upon galanin expression. In particular, galanin decreased activity, increased rest, decreased latency to rest at night, and decreased responsiveness to all stimuli examined (Figs. 5I,J, 6, 7I,J, 8E). These sedating effects directly support a role for galanin in promoting rest.

\section{Cck}

Acute administration of cck produces panic attacks in humans (de Montigny, 1989). Similarly, activation of the cck pathway increases anxiety-like behaviors in rodents, as measured by changes in locomotor behavior in the elevated plus maze, the light-dark test, and activity in an open field, while blockade of cck receptors attenuates these behaviors (Bowers et al., 2012). In zebrafish larvae, cck induced a unique rest/wake behavioral profile: waking activity was substantially elevated, yet total rest remained unchanged (Figs. 5E,F, 6A,B). Notably, cck induced sustained, contiguous bouts of locomotor activity (Fig. 6G,L). These lengthy movement bouts may represent a "locomotor style" that reflects an anxiety-like state in larval zebrafish (Clark et al., 2011).

\section{Nociceptin}

In rodents, intracerebroventricular administration of nociceptin suppresses locomotor activity (Reinscheid et al., 1995; Devine et al., 1996), while disruption of nociceptin signaling enhances motor behaviors (Rizzi et al., 2011). In addition, nociceptin suppresses anxiety-like behaviors in rodents. Specifically, nociceptin decreases aversion to novel or stressful environments in the several tests that measure locomotor activity preference, including the light-dark box, the elevated plus maze, and exploratory behaviors within a novel environment (Jenck et al., 1997). Similarly, loss-of-function of nociceptin or its receptor induces changes in locomotor activity indicative of an anxiety-like state (Köster et al., 1999; Reinscheid and Civelli, 2002; Gavioli et al., 2007; Rizzi et al., 2011). In our assays, nociceptin reduced waking activity and increased rest (Figs. $5 \mathrm{~K}, L, 6 \mathrm{~A}, \mathrm{~B}$ ). In addition, movement bout lengths induced by nociceptin expression were the shortest of all peptides tested (Figs. 6G,O, 9A). Thus our data suggest that nociceptin suppresses spontaneous locomotion, and that this function is conserved from fish to mammals.

\section{Sensory responsiveness}

\section{Hypocretin}

There have been conflicting reports regarding a role for hypocretin in modulating sensory responsiveness in mammals. For example, it has been suggested that administration of hypocretin to the brain can reduce responsiveness to acoustic stimuli (Singareddy et al., 2006), or have no effect (Jones et al., 2001). In contrast, another study suggested that hypocretin signaling enhances sensitivity to these stimuli: pharmacological inhibition of hypocretin signaling decreased responsiveness to acoustic bursts (Steiner et al., 2012). To our knowledge, a role for hypocretin in modulating responsiveness to visual startle or acute changes in illumination has not been previously explored. Here, expression of hypocretin increased responsiveness to dark-flash stimuli (Fig. $3 E$ ), suggesting an additional role for hypocretin apart from its well characterized functions in stabilizing wakefulness (Sakurai, 2007; Carter et al., 2013). In contrast, responses to thermal and mechanical/acoustic stimuli were unchanged upon hypocretin expression (Fig. $3 F, G$ ). Our assays therefore suggest hypocretin has modality-specific functions in sensory responsiveness, and specifically enhances responsiveness to changes in illumination.

\section{Nociceptin}

In mice, pharmacological activation of nociceptin signaling disrupts sensorimotor gating mediated by visual stimuli, but not by acoustic stimuli (Ces et al., 2012), suggesting that this peptide may independently modulate circuits underlying response to different sensory modalities. In contrast, intracerebroventricular injection of nociceptin in mice does not alter responsiveness to thermal stimuli, as assayed by reaction latency in a hot-plate test (Reinscheid et al., 1995). Our assays suggest that nociceptin function is similar between zebrafish and mammals. In particular, nociceptin attenuated responses to changes in illumination (Fig. $7 \mathrm{~K}$ ) without affecting sensitivity to mechanical (Fig. $7 \mathrm{~L}$ ) or thermal (Fig. $8 F$ ) stimuli.

\section{Cgrp}

Several studies have suggested mechanosensory functions for cgrp. For example, cgrp is expressed in hair cells both in vertebrate ears (Takeda et al., 1987) and in the amphibian lateral line organ (Adams et al., 1987). In addition, infusion of cgrp into the brain has been shown to potentiate the acoustic startle response in rats (Sink et al., 2011). In contrast, intracerebroventricular administration of cgrp decreases responsiveness to thermal stimuli in rats, but only at high doses (Pecile et al., 1987), while effects of cgrp upon visual startle or other responses to rapid changes in illumination are unknown. Our assays suggest that a mechanosensory function may be conserved in fish. In particular, cgrp increased overall levels of response to all stimulus modalities 
tested (Figs. $7 G, H, 8 D$ ), but specifically decreased the reaction time to tap stimuli (Fig. $7 H$ ).

\section{Adcyap $1 b$}

Infusion of adcyap1 into the rat brain enhances acoustic startle behaviors (Hammack et al., 2009). Interestingly, the sensory phenotypes induced by adcyap $1 \mathrm{~b}$ in larval zebrafish were similar to those induced by cgrp, suggesting conservation of a mechanosensory function. Roles for mammalian adcyap $1 \mathrm{~b}$ in modulating responsiveness to stimuli of other modalities are less clear. Injection of this peptide into peripheral tissues in rat enhances injury-sensitized thermal responsiveness without altering baseline responses to thermal stimuli (Sándor et al., 2009), while a role for adcyap $1 \mathrm{~b}$ in modulating responses to acute changes in illumination has not been described. In our assays, adcyap $1 b$ enhanced responsiveness to both thermal stimuli and changes in illumination.

\section{Cart}

In mouse, cart is a specific marker of ON-OFF direction-selective retinal ganglion cells, which respond to light onset and termination (Kay et al., 2011), suggesting that cart may function in detecting changes in illumination. Our assays provide behavioral support for this hypothesis. In particular, response latency to dark-flash stimuli was specifically decreased upon cart expression, suggesting a modality-specific role for this peptide (Fig. 7C). Effects of mammalian cart upon stimuli of other modalities are less clear. Though intracerebroventricular administration of cart in mice can decrease response to acoustic startle and thermal stimuli (Bannon et al., 2001; Damaj et al., 2003), the dose of cart used in these studies approaches levels that impair locomotor function (Damaj et al., 2003). In larval zebrafish, expression of cart enhanced responsiveness to stimuli of all modalities tested (Figs. 7C,D, 8B).

\section{Discussion}

Our study makes four contributions to the study of arousal: we develop high-throughput and sensitive assays for arousal in zebrafish larvae, provide the first parallel and thus directly comparable analysis of neuropeptidergic modulation of arousal in vertebrates, demonstrate that spontaneous activity and sensory responsiveness are separable aspects of arousal state, and reveal novel, unexpected, or conserved functions for neuropeptides in arousal.

\section{Arousal behaviors}

We employ two behavioral indicators of arousal: spontaneous locomotion and sensory responsiveness. Our analysis overcomes limitations of previous high-throughput but low-temporal resolution studies (Prober et al., 2006; Rihel et al., 2010). Notably, the improved temporal resolution enables analysis of individual movements and delineates quantitative characteristics (movement duration, frequency, amplitude, density) that generate broad differences in locomotor activity. We similarly dissect sensory responsiveness by quantifying stimulus threshold, response probability, and latency of response to various stimuli. We thus elucidate discrete parameters underlying complex behaviors, thereby highlighting subtle behavioral differences and facilitating comparisons across experiments.

Clustering of behavioral phenotypes highlighted commonalities and differences between different neuropeptides. For example, we identified a peptide (cgrp) that induced locomotor behaviors similar to those induced by hypocretin, peptides (cck and nociceptin) that induced unique profiles of locomotor activ- ity, peptides that specifically influenced locomotor activity (cck) versus sensory responsiveness (cart and adcyap $1 \mathrm{~b}$ ), and peptides that induced modality-specific changes in sensory responsiveness (hypocretin, adcyap1b, cart, cgrp, nociceptin). Quantitative modeling indicated that we explored much of the potential range of arousal behaviors in larval zebrafish. Behavioral clustering is a powerful tool to link experimental manipulations with relevant biochemical and neuronal pathways (Rihel et al., 2010). The work presented here thus enables systematic comparisons of arousal phenotypes induced by genetic and pharmacological manipulations, and will facilitate elucidation of shared biochemical or neuroanatomical functions underlying arousal.

\section{Partitioning of arousal}

The operational definition of arousal (Pfaff, 2006) - that an aroused animal moves more and is more responsive to stimulihas stimulated debate regarding the unitary versus partitioned nature of arousal (Jing et al., 2009; Lebestky et al., 2009; Van Swinderen and Andretic, 2011). Here, neuropeptide expression clearly uncouples spontaneous locomotor activity from sensory responsiveness, and further partitions each into independent behavioral components. Thus our experiments support the hypothesis that arousal is behaviorally separable.

One way to partition behaviors is via differential activity of distinct neuronal circuits. For example, dopaminergic influences upon locomotor activity and sensory responsiveness in Drosophila are governed by distinct circuitry. Tissue-specific functional rescue in dopamine receptor mutants indicates that circuits that mediate startle responses are distinct from those that regulate rest-wake behaviors (Lebestky et al., 2009). Similarly, the serotonergic dorsal raphe nucleus (DRN) in larval zebrafish increases visual responsiveness, but not locomotor activity, after an arousing stimulus (Yokogawa et al., 2012). Thus distinct arousal-regulating systems may regulate distinct arousal-related behaviors, and the broad range of behaviors observed here may reflect differential neuropeptidergic activity within individual arousal-generating systems.

Our results also indicate that these systems may be coordinately regulated. For example, cgrp enhanced both spontaneous locomotion and sensory responsiveness, while galanin exerted the opposite effects. Similarly, cart and adcyap1b increased responsiveness to stimuli of all modalities tested. These results suggest that behavioral components of arousal can be both uniformly controlled and independently regulated.

\section{Neuropeptide functions in arousal}

Our systematic analysis of arousal phenotypes allows us to suggest functions for neuropeptides via several approaches: we identify conserved and potentially ancestral arousal-related functions, test functions suggested by mammalian studies, propose novel functions for neuropeptides in regulating arousal behaviors, and identify potential antagonistic or cooperative interactions among neuropeptides.

\section{Conserved functions}

In mammals, hypocretin neurons innervate several arousalpromoting centers (Carter et al., 2013), and optogenetic activation of these neurons promotes wakefulness (Adamantidis et al., 2007; Carter et al., 2010). Our results strengthen the previous conclusion (Prober et al., 2006) that these functions are conserved. Specifically, hypocretin increased activity and decreased rest, primarily by increasing frequency of movements.

In mammals, nociceptin suppresses locomotion (Reinscheid et al., 1995; Devine et al., 1996; Rizzi et al., 2011), and is associated 
with visual sensorimotor gating (Ces et al., 2012). Similarly, nociceptin reduced spontaneous activity and decreased responsiveness to dark-flash stimuli in larval zebrafish.

Mechanosensory functions have been proposed for both adcyap 1 and cgrp in mammals (Adams et al., 1987; Takeda et al., 1987; Hammack et al., 2009; Sink et al., 2011). Both of these peptides specifically decreased response latency to tap stimuli in our assays, suggesting that these mechanosensory functions may be conserved.

Neuropeptides that elevated arousal-related behaviors in our assays (adcyap 1b, cgrp, cart, cck, and hypocretin) have each been associated with anxiety or stress in vertebrates (Kask et al., 2000; Hashimoto et al., 2001; Chaki et al., 2003; Hammack et al., 2009; Ressler et al., 2011; Sink et al., 2011; Johnson et al., 2012). Inappropriately elevated arousal is associated with disorders of anxiety, and is a defining feature of stress (Pfaff et al., 2007; de Lecea et al., 2012). Cck and nociceptin are among the best-studied examples of neuropeptide function in anxiety: Cck induces anxiety behaviors in mammals (Bowers et al., 2012), while nociceptin reduces these behaviors (Jenck et al., 1997). Interestingly, these peptides induced striking and opposite changes to locomotor bout length in larval zebrafish. In particular, cck expression caused extended bouts of locomotion, whereas bout lengths induced by nociceptin were the shortest of all peptides examined. Locomotor bout length may correlate with arousal state stability, and deviation from normal ranges could reflect defects in consolidation or maintenance of arousal. Extended bout lengths could be indicative of inappropriately stabilized arousal, and may reflect an anxiety-like state.

\section{Proposed functions}

Galanin is proposed to be a sleep-promoting peptide (Saper et al., 2005), but its in vivo behavioral effects have not been elucidated. We find that galanin decreased both spontaneous locomotion and sensory responsiveness, supporting a generally sedating role for galanin.

Injection of cart into the rat brain has been reported to increase wakefulness (Keating et al., 2010). Cart can also induce anxiety-like behaviors (Kask et al., 2000; Chaki et al., 2003); therefore, the increased wakefulness upon cart administration might have resulted from stressful stimuli during handling and injection (Keating et al., 2010). Our study suggests that cart primarily enhances sensory responsiveness: cart expression increased responsiveness to all sensory stimuli tested, but did not affect spontaneous locomotor activity.

\section{Novel functions}

Though cgrp promotes anxiety-like behaviors in rodents (Sink et al., 2011), an explicit function in arousal has not been previously described. Expression analysis suggests that cgrp interacts with multiple arousal-generating centers. For example, both cgrp and a cgrp receptor component are localized to the locus ceruleus and the DRN of rat (Ma et al., 2003). In our assays, cgrp induced locomotor behaviors strikingly similar to those induced by hypocretin; in addition, and in contrast to hypocretin, cgrp elevated responsiveness to all sensory stimuli examined. Therefore cgrp may function similarly to hypocretin in elevating activity, but may have additional roles in modulating sensory responsiveness.

While nociceptin induced modality-specific effects upon responsiveness to changes in illumination (Fig. $7 K$ ), consistent with its proposed role in mediating visual sensorimotor gating (Ces et al., 2012), functions for additional neuropeptides in mediating response to acute changes in illumination have not been described. In our assays, galanin decreased responsiveness to dark-flash stimuli, while adcyap1b, cart, hypocretin, and cgrp increased responsiveness. Furthermore, both hypocretin and cart exerted modality-specific effects: cart specifically decreased response latency to dark-flash stimuli, while hypocretin specifically increased responsiveness to these stimuli. Because serotonergic projections from the DRN to the optic tectum specifically modulate sensitivity to optical stimuli in larval zebrafish (Yokogawa et al., 2012), it may be interesting to determine whether the neuropeptides that alter responsiveness to the dark-flash stimuli may interact with this DRN-tectal circuit.

\section{Antagonistic and shared functions}

Similar or opposing behavioral changes induced by neuropeptides may indicate shared sites of activity or mechanisms of function. For example, cgrp and hypocretin may similarly act upon arousal-generating centers to promote wakefulness. In contrast, cgrp and galanin induced opposite behavioral phenotypes, and might therefore exert antagonizing effects upon common targets. Similarly, cck and nociceptin induced opposite changes in locomotor bout length, potentially reflecting antagonistic roles for these peptides in modulating anxiety-like behaviors.

Our study lays the foundation for a large-scale analysis of neuropeptidergic regulation of arousal and raises the question how the diverse behavioral effects induced by neuropeptides are caused at the circuit level (Schier, 2013). Precise manipulations of peptide function at the genetic or cellular level will be needed to test where arousal is modulated, e.g., by sensitization peripherally and/or centrally. In vivo interrogation of neuronal activity will be required to determine whether arousal-generating systems are highly discrete and specialized and thus regulate specific behaviors (Lebestky et al., 2009; Saper et al., 2010; Yokogawa et al., 2012) or are functionally redundant and distributed to protect against localized damage (Pfaff and Banavar, 2007; Pfaff et al., 2008). Finally, our gain-of-function assays will need to be complemented by loss-of-function approaches that reveal the essential roles of these and other neuropeptides.

\section{References}

Adamantidis AR, Zhang F, Aravanis AM, Deisseroth K, de Lecea L (2007) Neural substrates of awakening probed with optogenetic control of hypocretin neurons. Nature 450:420-424. CrossRef Medline

Adams JC, Mroz EA, Sewell WF (1987) A possible neurotransmitter role for CGRP in a hair-cell sensory organ. Brain Res 419:347-351. CrossRef Medline

Agmo A (2011) On the intricate relationship between sexual motivation and arousal. Horm Behav 59:681-688. CrossRef Medline

Alt B, Reibe S, Feitosa NM, Elsalini OA, Wendl T, Rohr KB (2006) Analysis of origin and growth of the thyroid gland in zebrafish. Dev Dyn 235:18721883. CrossRef Medline

Bannon AW, Seda J, Carmouche M, Francis JM, Jarosinski MA, Douglass J (2001) Multiple behavioral effects of cocaine- and amphetamineregulated transcript (CART) peptides in mice: CART 42-89 and CART 49-89 differ in potency and activity. J Pharmacol Exp Ther 299:10211026. Medline

Bargmann CI (2012) Beyond the connectome: how neuromodulators shape neural circuits. Bioessays 34:458-465. CrossRef Medline

Berridge CW, España RA, Vittoz NM (2010) Hypocretin/orexin in arousal and stress. Brain Res 1314:91-102. CrossRef Medline

Blechman J, Borodovsky N, Eisenberg M, Nabel-Rosen H, Grimm J, Levkowitz G (2007) Specification of hypothalamic neurons by dual regulation of the homeodomain protein Orthopedia. Development 134:4417-4426. CrossRef Medline

Bowers ME, Choi DC, Ressler KJ (2012) Neuropeptide regulation of fear and anxiety: Implications of cholecystokinin, endogenous opioids, and neuropeptide Y. Physiol Behav 107:699-710. CrossRef Medline 
Burgess HA, Granato M (2007a) Sensorimotor gating in larval zebrafish. J Neurosci 27:4984-4994. CrossRef Medline

Burgess HA, Granato M (2007b) Modulation of locomotor activity in larval zebrafish during light adaptation. J Exp Biol 210:2526-2539. CrossRef Medline

Carter ME, Yizhar O, Chikahisa S, Nguyen H, Adamantidis A, Nishino S, Deisseroth K, de Lecea L (2010) Tuning arousal with optogenetic modulation of locus coeruleus neurons. Nat Neurosci 13:1526-1533. CrossRef Medline

Carter ME, de Lecea L, Adamantidis A (2013) Functional wiring of hypocretin and LC-NE neurons: implications for arousal. Front Behav Neurosci 7:43. CrossRef Medline

Ces A, Reiss D, Walter O, Wichmann J, Prinssen EP, Kieffer BL, Ouagazzal AM (2012) Activation of nociceptin/orphanin FQ peptide receptors disrupts visual but not auditory sensorimotor gating in BALB/cByJ mice: comparison to dopamine receptor agonists. Neuropsychopharmacology 37:378-389. CrossRef Medline

Chaki S, Kawashima N, Suzuki Y, Shimazaki T, Okuyama S (2003) Cocaineand amphetamine-regulated transcript peptide produces anxiety-like behavior in rodents. Eur J Pharmacol 464:49-54. CrossRef Medline

Chiu CN, Prober DA (2013) Regulation of zebrafish sleep and arousal states: current and prospective approaches. Front Neural Circuits 7:58. CrossRef Medline

Clark JT, Kalra PS, Crowley WR, Kalra SP (1984) Neuropeptide Y and human pancreatic polypeptide stimulate feeding behavior in rats. Endocrinology 115:427-429. CrossRef Medline

Clark KJ, Boczek NJ, Ekker SC (2011) Stressing zebrafish for behavioral genetics. Rev Neurosci 22:49-62. CrossRef Medline

Colten HR, Altevogt BM (2006) Sleep disorders and sleep deprivation: an unmet public health problem. Washington, DC: National Academy of Sciences.

Crawley JN, Corwin RL (1994) Biological actions of cholecystokinin. Peptides 15:731-755. CrossRef Medline

Damaj MI, Martin BR, Kuhar MJ (2003) Antinociceptive effects of supraspinal rat cart (55-102) peptide in mice. Brain Res 983:233-236. CrossRef Medline

de Montigny C (1989) Cholecystokinin tetrapeptide induces panic-like attacks in healthy volunteers. Preliminary findings. Arch Gen Psychiatry 46:511-517. CrossRef Medline

de Lecea L, Carter ME, Adamantidis A (2012) Shining light on wakefulness and arousal. Biol Psychiatry 71:1046-1052. CrossRef Medline

Devine DP, Taylor L, Reinscheid RK, Monsma FJ Jr, Civelli O, Akil H (1996) Rats rapidly develop tolerance to the locomotor-inhibiting effects of the novel neuropeptide orphanin FQ. Neurochem Res 21:1387-1396. CrossRef Medline

Fuller PM, Fuller P, Sherman D, Pedersen NP, Saper CB, Lu J (2011) Reassessment of the structural basis of the ascending arousal system. J Comp Neurol 519:933-956. CrossRef Medline

Garey J, Goodwillie A, Frohlich J, Morgan M, Gustafsson JA, Smithies O, Korach KS, Ogawa S, Pfaff DW (2003) Genetic contributions to generalized arousal of brain and behavior. Proc Natl Acad Sci U S A 100: 11019-11022. CrossRef Medline

Garrison JL, Macosko EZ, Bernstein S, Pokala N, Albrecht DR, Bargmann CI (2012) Oxytocin/vasopressin-related peptides have an ancient role in reproductive behavior. Science 338:540-543. CrossRef Medline

Gavioli EC, Rizzi A, Marzola G, Zucchini S, Regoli D, Calo' G (2007) Altered anxiety-related behavior in nociceptin/orphanin FQ receptor gene knockout mice. Peptides 28:1229-1239. CrossRef Medline

Hammack SE, Cheung J, Rhodes KM, Schutz KC, Falls WA, Braas KM, May V (2009) Chronic stress increases pituitary adenylate cyclase-activating peptide (PACAP) and brain-derived neurotrophic factor (BDNF) mRNA expression in the bed nucleus of the stria terminalis (BNST): roles for PACAP in anxiety-like behavior. Psychoneuroendocrinology 34:833843. CrossRef Medline

Hashimoto H, Shintani N, Tanaka K, Mori W, Hirose M, Matsuda T, Sakaue M, Miyazaki J, Niwa H, Tashiro F, Yamamoto K, Koga K, Tomimoto S, Kunugi A, Suetake S, Baba A (2001) Altered psychomotor behaviors in mice lacking pituitary adenylate cyclase-activating polypeptide (PACAP). Proc Natl Acad Sci U S A 98:13355-13360. CrossRef Medline

Jenck F, Moreau JL, Martin JR, Kilpatrick GJ, Reinscheid RK, Monsma FJ Jr, Nothacker HP, Civelli O (1997) Orphanin FQ acts as an anxiolytic to attenuate behavioral responses to stress. Proc Natl Acad Sci U S A 94: 14854-14858. CrossRef Medline

Jing J, Gillette R, Weiss KR (2009) Evolving concepts of arousal: insights from simple model systems. Rev Neurosci 20:405-427. Medline

Johnson PL, Molosh A, Fitz SD, Truitt WA, Shekhar A (2012) Orexin, stress, and anxiety/panic states. Prog Brain Res 198:133-161. CrossRef Medline

Jones DN, Gartlon J, Parker F, Taylor SG, Routledge C, Hemmati P, Munton RP, Ashmeade TE, Hatcher JP, Johns A, Porter RA, Hagan JJ, Hunter AJ, Upton N (2001) Effects of centrally administered orexin-B and orexin-A: a role for orexin-1 receptors in orexin-B-induced hyperactivity. Psychopharmacology 153:210-218. CrossRef Medline

Kask A, Schiöth HB, Mutulis F, Wikberg JE, Rägo L (2000) Anorexigenic cocaine- and amphetamine-regulated transcript peptide intensifies fear reactions in rats. Brain Res 857:283-285. CrossRef Medline

Kawakami K (2004) Transgenesis and gene trap methods in zebrafish by using the Tol2 transposable element. Methods Cell Biol 77:201-222. CrossRef Medline

Kay JN, De la Huerta I, Kim IJ, Zhang Y, Yamagata M, Chu MW, Meister M, Sanes JR (2011) Retinal ganglion cells with distinct directional preferences differ in molecular identity, structure, and central projections. J Neurosci 31:7753-7762. CrossRef Medline

Keating GL, Kuhar MJ, Bliwise DL, Rye DB (2010) Wake promoting effects of cocaine and amphetamine-regulated transcript (CART). Neuropeptides 44:241-246. CrossRef Medline

Köster A, Montkowski A, Schulz S, Stübe EM, Knaudt K, Jenck F, Moreau JL, Nothacker HP, Civelli O, Reinscheid RK (1999) Targeted disruption of the orphanin $\mathrm{FQ} /$ nociceptin gene increases stress susceptibility and impairs stress adaptation in mice. Proc Natl Acad Sci U S A 96:1044410449. CrossRef Medline

Kovács A, Telegdy G, Tóth G, Penke B (1999) Neurotransmitter-mediated open-field behavioral action of CGRP. Life Sci 64:733-740. CrossRef Medline

Kumar S, Hedges SB (1998) A molecular timescale for vertebrate evolution. Nature 392:917-920. CrossRef Medline

Lebestky T, Chang JS, Dankert H, Zelnik L, Kim YC, Han KA, Wolf FW, Perona P, Anderson DJ (2009) Two different forms of arousal in Drosophila are oppositely regulated by the dopamine $\mathrm{d} 1$ receptor ortholog DopR via distinct neural circuits. Neuron 64:522-536. CrossRef Medline

Lleras-Forero L, Tambalo M, Christophorou N, Chambers D, Houart C, Streit A (2013) Neuropeptides: developmental signals in placode progenitor formation. Dev Cell 26:195-203. CrossRef Medline

Ma W, Chabot JG, Powell KJ, Jhamandas K, Dickerson IM, Quirion R (2003) Localization and modulation of calcitonin gene-related peptide-receptor component protein-immunoreactive cells in the rat central and peripheral nervous systems. Neuroscience 120:677-694. CrossRef Medline

Mahowald MW, Schenck CH (2005) Insights from studying human sleep disorders. Nature 437:1279-1285. CrossRef Medline

Moruzzi G, Magoun HW (1949) Brain stem reticular formation and activation of the EEG. Electroencephalogr Clin Neurophysiol 1:455-473. CrossRef Medline

Nakazato M, Murakami N, Date Y, Kojima M, Matsuo H, Kangawa K, Matsukura S (2001) A role for ghrelin in the central regulation of feeding. Nature 409:194-198. CrossRef Medline

Nishio S, Gibert Y, Berekelya L, Bernard L, Brunet F, Guillot E, Le Bail JC, Sánchez JA, Galzin AM, Triqueneaux G, Laudet V (2012) Fasting induces CART down-regulation in the zebrafish nervous system in a cannabinoid receptor 1-dependent manner. Mol Endocrinol 26:1316-1326. CrossRef Medline

Pecile A, Guidobono F, Netti C, Sibilia V, Biella G, Braga PC (1987) Calcitonin gene-related peptide antinociceptive activity in rats, comparison with calcitonin. Regul Pept 18:189-199. CrossRef Medline

Pedersen CA, Prange AJ Jr (1979) Induction of maternal behavior in virgin rats after intracerebroventricular administration of oxytocin. Proc Natl Acad Sci U S A 76:6661-6665. CrossRef Medline

Pfaff D (2006) Brain arousal and information theory: neural and genetic mechanisms. Cambridge, MA: Harvard UP.

Pfaff D, Banavar JR (2007) A theoretical framework for CNS arousal. Bioessays 29:803-810. CrossRef Medline

Pfaff DW, Martin EM, Ribeiro AC (2007) Relations between mechanisms of CNS arousal and mechanisms of stress. Stress 10:316-325. CrossRef Medline

Pfaff D, Ribeiro A, Matthews J, Kow LM (2008) Concepts and mechanisms 
of generalized central nervous system arousal. Ann NY Acad Sci 1129:1125. CrossRef Medline

Pieribone VA, Xu ZQ, Zhang X, Grillner S, Bartfai T, Hökfelt T (1995) Galanin induces a hyperpolarization of norepinephrine-containing locus coeruleus neurons in the brainstem slice. Neuroscience 64:861-874. CrossRef Medline

Podlasz P, Sallinen V, Chen YC, Kudo H, Fedorowska N, Panula P (2012) Galanin gene expression and effects of its knock-down on the development of the nervous system in larval zebrafish. J Comp Neurol 520:38463862. CrossRef Medline

Prober DA, Rihel J, Onah AA, Sung RJ, Schier AF (2006) Hypocretin/orexin overexpression induces an insomnia-like phenotype in zebrafish. J Neurosci 26:13400-13410. CrossRef Medline

Prober DA, Zimmerman S, Myers BR, McDermott BM Jr, Kim SH, Caron S, Rihel J, Solnica-Krezel L, Julius D, Hudspeth AJ, Schier AF (2008) Zebrafish TRPA1 channels are required for chemosensation but not for thermosensation or mechanosensory hair cell function. J Neurosci 28: 10102-10110. CrossRef Medline

Ressler KJ, Mercer KB, Bradley B, Jovanovic T, Mahan A, Kerley K, Norrholm SD, Kilaru V, Smith AK, Myers AJ, Ramirez M, Engel A, Hammack SE, Toufexis D, Braas KM, Binder EB, May V (2011) Post-traumatic stress disorder is associated with PACAP and the PAC1 receptor. Nature 470: 492-497. CrossRef Medline

Reinscheid RK, Civelli O (2002) The orphanin FQ/nociceptin knockout mouse: a behavioral model for stress responses. Neuropeptides 36:72-76. CrossRef Medline

Reinscheid RK, Nothacker HP, Bourson A, Ardati A, Henningsen RA, Bunzow JR, Grandy DK, Langen H, Monsma FJ Jr, Civelli O (1995) Orphanin FQ: a neuropeptide that activates an opioidlike $\mathrm{G}$ protein-coupled receptor. Science 270:792-794. CrossRef Medline

Rihel J, Prober DA, Arvanites A, Lam K, Zimmerman S, Jang S, Haggarty SJ, Kokel D, Rubin LL, Peterson RT, Schier AF (2010) Zebrafish behavioral profiling links drugs to biological targets and rest/wake regulation. Science 327:348-351. CrossRef Medline

Rizzi A, Molinari S, Marti M, Marzola G, Calo' G (2011) Nociceptin/orphanin FQ receptor knockout rats: in vitro and in vivo studies. Neuropharmacology 60:572-579. CrossRef Medline

Robbins TW (1997) Arousal systems and attentional processes. Biol Psychol 45:57-71. CrossRef Medline

Rogge G, Jones D, Hubert GW, Lin Y, Kuhar MJ (2008) CART peptides: regulators of body weight, reward and other functions. Nat Rev Neurosci 9:747-758. CrossRef Medline

Rotzinger S, Lovejoy DA, Tan LA (2010) Behavioral effects of neuropeptides in rodent models of depression and anxiety. Peptides 31:736-756. CrossRef Medline

Sándor K, Bölcskei K, McDougall JJ, Schuelert N, Reglodi D, Elekes K, Petho G, Pintér E, Szolcsányi J, Helyes Z (2009) Divergent peripheral effects of pituitary adenylate cyclase-activating polypeptide-38 on nociception in rats and mice. Pain 141:143-150. CrossRef Medline

Sakurai T (2007) The neural circuit of orexin (hypocretin): maintaining sleep and wakefulness. Nat Rev Neurosci 8:171-181. CrossRef Medline

Sakurai T, Amemiya A, Ishii M, Matsuzaki I, Chemelli RM, Tanaka H, Williams SC, Richardson JA, Kozlowski GP, Wilson S, Arch JR, Buckingham RE, Haynes AC, Carr SA, Annan RS, McNulty DE, Liu WS, Terrett JA, Elshourbagy NA, Bergsma DJ et al. (1998) Orexins and orexin recep- tors: a family of hypothalamic neuropeptides and G protein-coupled receptors that regulate feeding behavior. Cell 92:573-585. CrossRef Medline

Saper CB, Scammell TE, Lu J (2005) Hypothalamic regulation of sleep and circadian rhythms. Nature 437:1257-1263. CrossRef Medline

Saper CB, Fuller PM, Pedersen NP, Lu J, Scammell TE (2010) Sleep state switching. Neuron 68:1023-1042. CrossRef Medline

Schier AF (2013) Should I stay or should I go: neuromodulators of behavioral states. Cell 154:955-956. CrossRef Medline

Schorscher-Petcu A, Austin JS, Mogil JS, Quirion R (2009) Role of central calcitonin gene-related peptide (CGRP) in locomotor and anxiety- and depression-like behaviors in two mouse strains exhibiting a CGRPdependent difference in thermal pain sensitivity. J Mol Neurosci 39:125136. CrossRef Medline

Seutin V, Verbanck P, Massotte L, Dresse A (1989) Galanin decreases the activity of locus coeruleus neurons in vitro. Eur J Pharmacol 164:373-376. CrossRef Medline

Sherin JE, Elmquist JK, Torrealba F, Saper CB (1998) Innervation of histaminergic tuberomammillary neurons by GABAergic and galaninergic neurons in the ventrolateral preoptic nucleus of the rat. J Neurosci 18: 4705-4721. Medline

Singareddy R, Uhde T, Commissaris R (2006) Differential effects of hypocretins on noise-alone versus potentiated startle responses. Physiol Behav 89:650-655. CrossRef Medline

Sink KS, Walker DL, Yang Y, Davis M (2011) Calcitonin gene-related peptide in the bed nucleus of the stria terminalis produces an anxiety-like pattern of behavior and increases neural activation in anxiety-related structures. J Neurosci 31:1802-1810. CrossRef Medline

Södersten P, Henning M, Melin P, Ludin S (1983) Vasopressin alters female sexual behaviour by acting on the brain independently of alterations in blood pressure. Nature 301:608-610. CrossRef Medline

Steiner MA, Lecourt H, Jenck F (2012) The brain orexin system and almorexant in fearconditioned startle reactions in the rat. Psychopharmacology 223:465-475. CrossRef Medline

Szymusiak R, Alam N, Steininger TL, McGinty D (1998) Sleep-waking discharge patterns of ventrolateral preoptic/anterior hypothalamic neurons in rats. Brain Res 803:178-188. CrossRef Medline

Takeda N, Doi K, Mori N, Yamazaki H, Tohyama M, Matsunaga T (1987) Localization and fine structure of calcitonin gene-related peptide (CGRP)-like immunoreactive nerve fibres in the organ of Corti of guinea pigs by immunohistochemistry. Acta Otolaryngol 103:567-571. Medline

Van Swinderen B, Andretic R (2011) Dopamine in Drosophila: setting arousal thresholds in a miniature brain. Proc Biol Sci 278:906-913. CrossRef Medline

Vaudry D, Falluel-Morel A, Bourgault S, Basille M, Burel D, Wurtz O, Fournier A, Chow BK, Hashimoto H, Galas L, Vaudry H (2009) Pituitary adenylate cyclase-activating polypeptide and its receptors: 20 years after the discovery. Pharmacol Rev 61:283-357. CrossRef Medline

von Economo C (1930) Sleep as a problem of localization. J Nerv Ment Dis 71:249-259. CrossRef

Wolman M, Granato M (2012) Behavioral genetics in larval zebrafish: learning from the young. Dev Neurobiol 72:366-372. CrossRef Medline

Yokogawa T, Hannan MC, Burgess HA (2012) The dorsal raphe modulates sensory responsiveness during arousal in zebrafish. J Neurosci 32:1520515215. CrossRef Medline 